\title{
Neurokinin 3 Receptor Effects on Cognitive Behaviour in a Rat Model of Alzheimer's Disease
}

\section{Raviye Ozen Koca ( $\square$ raviyeozen@hotmail.com )}

Necmettin Erbakan University Meram Faculty of Medicine: Necmettin Erbakan Universitesi Meram Tip Fakultesi https://orcid.org/0000-0001-6295-5548

\section{Zulfikare Isik Solak Gormus}

Necmettin Erbakan University Meram Faculty of Medicine: Necmettin Erbakan Universitesi Meram Tip Fakultesi

\section{Hatice Solak}

Necmettin Erbakan University Meram Faculty of Medicine: Necmettin Erbakan Universitesi Meram Tip Fakultesi

\section{Aynur Koc}

Hitit University Faculty of Medicine: T C Hitit Universitesi Tip Fakultesi

İbrahim Kılınç

Necmettin Erbakan University Meram Faculty of Medicine: Necmettin Erbakan Universitesi Meram Tip Fakultesi

\section{Sinan lyisoy}

Necmettin Erbakan University Meram Faculty of Medicine: Necmettin Erbakan Universitesi Meram Tip Fakultesi

\section{Selim Kutlu}

Necmettin Erbakan University Meram Faculty of Medicine: Necmettin Erbakan Universitesi Meram Tip Fakultesi

\section{Research Article}

Keywords: Alzheimer's disease, neurokinin 3 receptor, learning and memory

Posted Date: May 19th, 2021

DOI: https://doi.org/10.21203/rs.3.rs-517911/v1

License: (c) (i) This work is licensed under a Creative Commons Attribution 4.0 International License. Read Full License 


\section{Abstract}

Alzheimer's disease (AD) is accepted as a form of progressive and irreversible dementia. It is known that cholinergic systems are commonly affected in AD. Neurokinin 3 receptor (NK3R) is involved in learning and memory related processes. Activation of NK3R is known to facilitate the release of many neurotransmitters such as acetylcholine (Ach), dopamine (DA), noradrenaline (NA). Based on this information, hypothesis of the study that NK3R agonism can have positive effects on behavioral and learning parameters through cholinergic and catecholaminergic mechanisms. The aim of this study was to investigate the effects of NK3R agonist senktide on cognitive and neurobehavioral mechanisms in model of $A D$.

50 adult male Wistar albino rats were obtained; Control, $A D$, Control+NK3R agonist, AD+NK3R agonist, $A D+N K 3 R$ agonist+antagonist groups. AD model was established by administering Aß1-42 intracerebroventricularly. Following NK3R agonist+antagonist injections, open field (OF) and Morris water maze (MWM) were applied for behavioral and learning parameters. Hippocampus and cortex tissues were extracted. Analysis of cholinergic mechanisms from these tissues were performed by ELISA method.

Group-time effect was significant in OF $(p<0.05)$. Distance moved parameter was significant between groups in MWM $(p<0.05)$. There was a significant difference between groups in AChE and ChAT levels $(p<0.05)$. DA concentrations of brainstem samples were significant $(p<0.05)$. There was no significant difference in NA concentration ( $p>0.05)$.

NK3R agonists were found to be effective in improving cognitive functions in rats with AD pathology. It has been observed that positive effects on learning and memory performances can be mediated by cholinergic mechanisms.

\section{Introduction}

Alzheimer's disease (AD), which is characterized by memory loss, cognitive dysfunction and mood changes, constitutes the majority of dementia patients [1]. AD is the major cause of dementia in the aging society and is thought to affect more than 35 million people worldwide [2]. It is estimated that 1 million new cases of AD will develop every year by 2050 [3].

$A D$ is an age-related neurodegenerative disease with characteristic clinical and pathological features [4]. $A D$ progressively causes mental, behavioral, functional damage, and loss of learning ability. The symptoms of the disease begin with a loss of working memory and in later stages there is a decrease in mental performance and learning ability. This disease is associated with amyloid $\beta$ peptide (AB) plaque formation, hyperphosphorylation of tau protein, neurofibrillary tangles (NT), loss of neuronal synapses, inflammation, oxidative damage, apoptosis and necrosis of brain cells [3]. Extracellular deposits of A $\beta$ in plaques and intracellular accumulation of NT formed by hyperphosphorylated tau protein are the most important pathological markers $[1,4]$. There are many data about age, genetics, head trauma, potential risk factors of $A D$. There are also important changeable risk factors such as cognitive capacity 
(intelligence, education), physical activity, obesity, alcohol and smoking. Many treatable diseases such as stroke, diabetes, hypertension and hypercholesterolemia increase the risk of $A D$ [5]. AD treatment options aim to alleviate the symptoms of the disease by inhibiting acetylcholinesterase (AchE) or by blocking abnormal N-methyl-D-aspartic acid (NMDA) receptor signaling. However, a definitive treatment of the disease is not yet available [1].

$A D$ is also characterized by degenerative changes in various neurotransmitter systems. Loss of neuronal synapses and neuronal death ultimately lead to a decrease in acetylcholine (ACh) and other neurotransmitters [4]. It has been reported that the reduction in ACh synthesis is due to reduced choline acetyltransferase (ChAT) enzyme, damage to cholinergic neurons and axons, and losses in cholinergic neurons projecting to the cortex and hippocampus. It has been reported that cholinergic loss in $A D$ is associated with various behavioral and psychiatric symptoms, such as depression, agitation, anxiety, and psychosis observed in patients. In addition to cholinergic dysfunction, irregularities and loss of neuron in catecholaminergic neurotransmission are thought to be effective in the occurrence of these symptoms [6]. The mechanism underlying memory dysfunction in old age and $A D$ is thought to be cholinergic hypofunction [7]. A marked decrease in ChAT activity and a significant loss of cells in basal forebrain neurons were detected in patients with $A D$ [8]. Treatment protocols for AD aim to increase the activity of the cholinergic neurotransmitter system by inhibition of AChE [9]. Although the cholinergic system plays an important role for dementia and cognitive symptoms of normal aging, it should not be overlooked that changes in other neurotransmitter systems, such as noradrenaline (NA), dopamine (DA) and serotonin, may also cause these pathologies [10].

Tachycinins, which is widely distributed in CNS, plays an important functional role in both physiological and pathological conditions [11]. Tachycinins is thought to have neurotransmitter, neuromodulator and neuroprotective roles [12]. In CNS, tachycinins, are found in regions that play a role especially in the regulation of various peripheral autonomic functions (blood pressure, respiration, gastrointestinal motility, etc.), mood-related functions (stereotyped behavior, motility, anxiety, aggression and pain) and higher cerebral functions (learning and memory) [11].

Neurokinin B (NKB) acts as the most potent natural agonist for the neurokinin 3 receptor (NK3R). Some agonists selective for NK3R, such as senktide, have been obtained by modification of the primary structure of NKB [13]. The physiological effects of NK3R in the mammalian central nervous system are not fully known. Various studies have been reported that activation of this receptor affects the release of many neurotransmitters such as ACh and DA. Studies based on these data have shown that NK3R plays a role in schizophrenia, Parkinson's disease, epilepsy, depression and memory processes [14].

NK3R is commonly found in the frontal cortex, amygdala, medial septum and hippocampus, which are areas based on learning and memory [15]. It has been shown that NK3R is expressed on cholinergic neurons [16] and such neurons in the septohippocampal cholinergic system are activated by NK3R agonists [17]. In addition, NK3R agonists cause ACh secretion [18] and protect cholinergic neurons in the basal forebrain from neurotoxicity [19]. Possible role of NK3R between learning and memory mechanism 
and cholinergic modulation in various studies is the expression of NK3R on cholinergic neurons and senktide administration with striatum, hippocampus [20] has been associated with increased extracellular ACh in the amygdala and prefrontal cortex [21]. The effect of senktide on cholinergic activation in the hippocampus and frontal cortex shows these structures as potential domains for promnestic effects. The activation of the septohippocampal and frontal cortex cholinergic pathways supports the promnestic effects of agonism created by senktide and NKB by improving ACh and memory [22].

In aged rats, subcutaneous senktide administration increased ACh in the hippocampus, amygdala and the frontal cortex, and also had anxiolytic, antidepressant and promnestic effects [23]. ICV senktide administration has also been found to induce anxiolytic-like effect in mice [24]. Based on the systemic and peripheral administration of senktide, it can be concluded that NK3R may have a modulating role in anxiety and learning processes and forebrain cholinergic systems may be likely to participate in these actions [25].

Despite positive effects on learning and memory in some animal models with the activation of NK3R by senktide administration $[20,21,26,27,28]$ there is still little evidence of neurodegenerative diseases. The effect of NK3R agonism and its activating effect on ACh [20] and expression of NK3R in cholinergic neurons [16] show the possible role of NK3R in learning and memory through cholinergic modulation. Senktide has also been reported to significantly improve episodic memory in rats with age-related memory loss [20].

Based on this information, it was aimed to investigate the effects of NK3R agonist senktide administration on cognitive functions and neurobehavioral mechanisms in the experimental $A D$ rat model. For this purpose, in the experimental AD model, it was aimed to determine how learning and memory tests, locomotor activity changed, to determine the level of cholinergic system activation, to determine the level of catecholaminergic neurotransmission.

\section{Materials And Methods}

\section{Ethics Statement}

The protocols of animal experiments were approved by the Local Ethics Committee of Application and Research Center of Experimental Medicine, Necmettin Erbakan University, No. 2016-050, on 30.09.2016.

\section{Experimental Protocol}

\section{Animals}

In this study, 50 male Wistar albino rats, 12 months old, were used. The care and feeding of the rats were done at Necmettin Erbakan University Experimental Medicine Application and Research Center. Rats were housed in plastic cages where they could move freely with food and water containers, their food and water were given as ad-libitum. Cages were cleaned weekly. The animals were stored at room temperature $\left(22 \pm 1^{\circ} \mathrm{C}\right)$ for 12 hours light/dark period under standard laboratory conditions. 
Animals were divided into 5 groups: 1) Control group $(C, n=10), 2)$ Alzheimer's disease group ( $A D, n=10)$, 3) Alzheimer's disease + NK3R agonist (Senktide) administered group ( $A D S, n=10)$, 4) Control + NK3R agonist administered group (CS, $n=10), 5)$ Alzheimer's disease + NK3R agonist + NK3R antagonist (Osanetant) administered group (ADSO, $n=10)$.

\section{Drug Administration}

$A \beta$ 1-42 (Sigma-Aldrich, USA) was used to construct the experimental Alzheimer's model in rats. The A $\beta$ peptide was dissolved in saline. It was left for incubation at $37^{\circ} \mathrm{C}$ for 72 hours and kept waiting for ICV injection. NK3R agonist senktide ([succinyl-Asp6-N-Me-Phe8] SP6-11; Bachem, Germany) was dissolved with $5 \%$ dimethylsulfoxide in phosphate buffered physiological saline (PBS). NK3R antagonist osanetant (SR142801, Sigma Aldrich, USA) was dissolved in 0.01\% Tween 80 (Sigma-Aldrich, Steinheim, Germany) in ultrapure water. Senktide and SR142801 were prepared in a volume of $1 \mathrm{mg} / \mathrm{kg}$ body weight. Senktide was administered subcutaneously at a dose of $0.2 \mathrm{mg} / \mathrm{kg}$ and osanetant was administered intraperitoneally at a dose of $6 \mathrm{mg} / \mathrm{kg}$. In the antagonist group, senktide was injected 1 minute after administration of osanetant. Control animals were injected with solvent. Doses were determined taking into account previous studies that showed a healing effect in learning and memory tests $[20,21,25,26$, $27,28]$.

\section{Intracerebroventricular $A \beta$ injections and neurosurgery}

Anesthesia was administered before ICV injection by the combination of ketamine $(100 \mathrm{mg} / \mathrm{kg})$ and xylazine ( $5 \mathrm{mg} / \mathrm{kg}$ ). After the anesthetic agent was administered, the head of the rats placed in the stereotaxic device was fixed with the ear sticks of the device. After the scalp was cut from the midline, Bregma, the reference point, was identified. The $A \beta$ 1-42 peptide was bilaterally injected into the $C A 3$ region of the hippocampus (AP: $-4.36 \mathrm{~mm}$, ML: $-4.4 \mathrm{~mm}$, and DV: $-8.0 \mathrm{~mm}$, Paxinos and Watson 2009) (Figure 3.1) using a micro injector ( $1 \mu$ l Hamilton) $(2.2 \mathrm{nmol} / 10 \mu \mathrm{l})$ to $A D$ model groups (AD, ADS and ADSO). Rats of $C$ and CS groups were injected with the same amount of saline as ICV (Figure 3.2). On the 15th day of behavior and memory experiments, the animals were first injected with the NK3R agonist senktide and the NK3R antagonist until the end of the experiment. On the 15th day, when the behavioral and memory experiments started, the animals were injected subcutaneously with the NK3R agonist senktide, and the NK3R antagonist osanetant was administered to ADSO group until the end of the experiment.

\section{Behavioral and Memory Tests}

OF and MWM tests were performed to evaluate the locomotor activity, anxiety-like behaviors, spatial memories of animals. OF test and MWM were carried out between 09:00-12:00 am. Animals were brought to the room where the test would be performed at least one hour before the test and adaptation to the environment was ensured. 
OF test was performed at the beginning and end of the experiment in order to evaluate the locomotor activities, some behaviors such as anxiety and depression of animals. OF test apparatus used is made of $80 \times 80 \times 30 \mathrm{~cm}$ square black plexiglass material. All test applications were recorded with the video recording system associated with the special software program (Ethovision Video Monitoring System XT11, The Netherlands) (Figure 3.4). With software program, two regions are determined in the test apparatus, center and edge. The parameters of the distance $(\mathrm{cm})$, speed $(\mathrm{cm} / \mathrm{s})$ and the number of entries from the edge to the center for 5 minutes were calculated with a software program. The rearing and grooming behaviors of the animals were scored manually. The test apparatus was cleaned with $10 \%$ ethyl alcohol solution after each animal $[29,30]$.

\section{Morris Water Maze Test (MWM)}

MWM consists of a circular water tank with a diameter of $180 \mathrm{~cm}$ and a depth of $60 \mathrm{~cm}$ and a $10 \times 10 \mathrm{~cm}$ hidden platform (Figure 3.5). The water tank was darkened with black paint to prevent the platform from being seen. The room where the experimental setup is located was illuminated with the light source. Different shapes were hanged on the walls of the room where the experiment was made, which could provide clues for the subjects. Attention was paid to making the experiment with the same team, to wear the same clothes during the experiment, to be quiet in the room and not to create an extra stimulus for the subjects. All rats were given a habituation swim the day before their experiment. On the day of the habituation, the platform was kept visible $1 \mathrm{~cm}$ above the water. The animals were floated for 60 seconds and the animals that could not find the platform were left on the platform and kept there for 20 seconds. The platform was held at a fixed point on the days of training, and the platform was removed from the pool on the day of the memory test (probe). In the training of the experiment, the rats were left to the pool 4 times in different directions consecutively every day. Rats were expected to find the hidden platform within 60 seconds. After staying on the platform for about 15 seconds, they were removed from the pool. In the memory test, the platform was removed from the pool and the rats swam for 60 seconds. All tests were recorded with a special software program (Figure 3.6). Distance moved, latency to the platform, number of passes through the target quadrant and time spent in the target quadrant parameters were analyzed.

\section{Ending the Experiment and Removing Tissues}

After the injections and behavioral tests were completed, the animals were decapitated under anesthesia, and the hippocampus, cortex and brainstem parts of the brain tissue on dry ice were separated according to the Paxinos and Watson rat brain atlas and placed in tubes. All tissues were kept at $-80{ }^{\circ} \mathrm{C}$ until analysis.

\section{Enzyme-linked immunosorbent assay (ELISA) analysis}

Rat hippocampus and cortex tissues were placed separately in tubes filled with cold phosphate buffer. Each hippocampus and cortex tissue sample of the rats in the same group was weighed and combined three by one to provide sufficient study sample. 
In the homogenization buffer containing the protease inhibitor cocktail. All homogenization steps are made in accordance with the cold chain. Homogenates were centrifuged at $10,000 \mathrm{~g}$ and $+4^{\circ} \mathrm{C}$ for 15 minutes using Hettich Rotina 46R (Hettich Zentrifugen, Tuttlingen, Germany) brand-cooled centrifuge and portioned to $-80^{\circ} \mathrm{C}$. Rat Choline Acetyltransferase (Catalog number: MBS161266, Sensitivity: $0.01 \mathrm{ng} / \mathrm{mL}$, $\% \mathrm{CV}:<10$ ) and Rat Acetylcholinesterase (Catalog number: MBS725468, Sensitivity: $1 \mathrm{pg} / \mathrm{mL}, \% \mathrm{CV}:<10$ ) levels were measured using the double antibody sandwich ELISA method in rat hippocampus and cortex tissue (MyBioSource, San Diego, CA, USA). Protein levels in rat hippocampus and cortex tissues were measured by spectrophotometric method using Pierce bicinchoninic acid-BCA kits (Thermo Scientific, Illinois, USA). Parameter levels in rat hippocampus and cortex tissues were standardized by dividing the results into protein concentrations. In spectrophotometric measurements, results were calculated according to the absorbance concentration calibration charts using the Bio-rad Microplate absorbance readerxMark system (Bio-rad Laboratories, California, USA).

\section{High performance liquid cromotography (HPLC) Analysis}

The brainstem tissues were weighed and mixed with $1 \mathrm{ml} 0.1 \mathrm{M}$ hydrochloric acid to determine the NA and DA monoamines. The homogenates were centrifuged at $14000 \mathrm{rpm}$ at $+4{ }^{\circ} \mathrm{C}$ for 15 minutes and their supernatants were separated. The supernatants were made ready for analysis in HPLC (Agilent Technologies 1260 brand; 250x4.6 mm C18 ODS analytical HPLC column) by passing them through a 0.2 $\mu \mathrm{m}$ microfilter. HPLC analysis interval was set to 5 . The temperature of the column oven was fixed at 40 ${ }^{\circ} \mathrm{C}$. With the cell section of the electrochemical detector (Waters 2465 electrochemical) in the open position, the analysis reference line was waited for 1 hour (equilibration process). Injections were carried out in $20 \mu$ volume (with Hamilton injector). Between sample injections, the injection unit of the device was washed with methanol.

\section{Statistical analysis}

Data analysis of the study was carried out with SAS University Edition 9.4 program. Descriptive statistics about variables are given. Mean \pm standard error $(A M \pm S E)$ for numerical variables, frequency and percentage values for qualitative variables were given. $p<0.05, p<0.01, p<0.0001$ was considered significant. The least squares averages were compared for the significant effects. Tukey-Kramer correction was used when necessary. Standard error plots of the mean squares of the relevant variables were drawn.

\section{Results}

Open Field Test

Distance moved parameter

The distance moved parameter showed a significant difference by time and group time interaction $(p<0.05)$. The second distance parameters were found to be decreased according to the first distance 
parameter of the groups (Table 1). There was no significant difference between the groups $(p=0.4185)$ (Fig. 1).

\section{Velocityparameter}

For the velocity, a significant difference was observed between two measurements according to time $(p<0.0001)$. There was no significant difference between the groups $(p=0.4185)$. It was observed that the group time interaction was statistically significant $(p<0.05)$. Second measurements were found to be decreased compared to the first velocity values of the groups. At the end of the experiment, the ADSO group had the lowest speed (Table 2 and Fig. 2).

\section{Movement parameter}

A significant difference was found between two measurements according to time $(p<0.0001)$. Groups effect $(p=0.7501)$ and group time interaction $(p=0.0969)$ were not statistically significant. It was observed that the second values decreased according to the first movement percentages of the groups. At the end of the experiment, the lowest percentage of movement was seen in the ADSO group (Table 3 and Fig. 3 ).

\section{Morris water maze}

\section{Latency to the platform parameter}

Latency to the platform was compared between groups, no statistically significant difference was found between the groups $(p=0.0908)$. The control group found the platform in less time compared to the other groups. The ADS group reached the platform in a shorter time than the AD and ADSO groups. Latency to the platform for the AD group and the ADSO group was close to each other (Table 4 and Fig. 4).

\section{Distance moved parameter}

When the distance moved during the test phase of MWM was compared, a statistically significant difference was found between the groups $(\mathrm{p}<0.0001)$ (Table 5 and Fig. 5$)$. In the comparison between groups, a significant difference was found between the AD group and the other groups $(p<0.05)$. The distance moved by the ADS group was significant compared to the ADSO and CS groups $(p<0.05)$. The distance moved by the ADSO group was significantly less than the $C$ group $(p<0.05)$. When the distance moved during the MWM test phase was compared, there was a visible difference between the groups.

\section{Number of passes through the target quadrant parameter}

In the test phase of MWM, the parameter of the number of passes from the target quadrant was found statistically significant between the groups $(p<0.05)$ (Table 6 and Fig. 8 ). It was observed that the ADS group had more passages through the target quadrant than the other groups.

In the comparison of the number of passes through the target quadrant between the groups, the AD group was found to be significant compared to the ADS and CS groups, the ADS group compared to the ADSO 
group, and the ADSO group compared to the $C$ and CS groups $(p<0.05)$.

\section{Time spent in the target quadrant parameter}

In the MWM test phase, a statistically significant difference was found between the groups for the parameter of the time spent in the target quadrant $(p<0.05)$ (Table 7). A significant difference was observed between the CS group and the AD and ADSO groups in terms of their stay in the target quadrant $(p<0.05)$ (Fig. 9).

\section{ELISA}

\section{Acetylcholinesterase (AChE) parameter}

The amount of AChE was determined in the hippocampus and cortex tissues by ELISA method. A statistically significant difference was found between groups and in group tissue interaction $(p<0.0001)$ (Table 8). There was no significant difference between tissues $(p=0.7005)$. The amount of hippocampus tissue AChE was found to be statistically significant between the AD group and the CS group and between the ADSO group and the CS group ( $p<0.01$ ) (Fig. 10). In the cortex tissue, a statistically significant difference was observed between the $C$ group and all groups $(p<0.0001)$ (Fig. 11).

\section{Choline asetyltransferase (ChAT) parameter}

ChAT amount was determined in hippocampus and cortex tissues by ELISA method. A statistically significant difference was found between groups $(p<0.05)$, between tissues and in group tissue interaction $(p<0.0001)$ (Table 9). A statistically significant difference was found in the amount of ChAT in hippocampus tissue between the AD group and the ADS and $C$ groups $(p<0.0001)$, and between the ADS group and the ADSO group ( $p<0.01$ ) (Fig. 12). A statistically significant difference was observed in the amount of ChAT in cortex tissue between the AD group and the ADS group $(p<0.01)$ and the $C$ group, between the ADS group and the ADSO group, between the ADSO group and the $C$ group, and between the $C$ group and CS group ( $p<0.0001)$ (Fig. 13).

\section{Monoamine Analysis}

\section{Catecholamines in brainstem}

NA and DA concentrations were evaluated in the brainstem samples in rats (Table 10).

\section{Noradrenaline analysis NA concentration in brainstem}

There was no significant difference between the groups in NA concentration ( $p>0.05)$ (Fig. 14). Although statistically significant was not seen, NA concentration of AD group was lower than all groups.

\section{DA concentration in brainstem}


DA concentration was found to be significantly different between the groups (Fig. 15). In the comparison of $D A$ concentrations between groups, $A D$ group was found to be significant compared to the $C$ group $(p<0.05)$, and the ADS group compared to the ADSO group $(p<0.01)$.

\section{Discussion}

The effect of NK3R agonism on ACh and the expression of NK3R in cholinergic neurons demonstrates the possible role of NK3R on cholinergic mechanisms [16, 23]. Although activation of NK3R by senktide administration has positive effects on learning and memory in some animal models $[20,21,26]$, there is still little evidence for neurodegenerative diseases. It has been reported that tachykinins significantly affect learning and memory [14].

It is thought that the underlying mechanism of memory dysfunction in old age and $A D$ is cholinergic hypofunction [7]. A significant decrease in ChAT activity and cell loss in the basal forebrain neuron number have been detected in patients with $A D[6]$. It has been reported that the decrease in ACh synthesis in $A D$ is due to the decrease in the amount of ChAT enzyme and choline reuptake, damage to cholinergic neurons and axons, and losses in cholinergic neurons projecting to the cortex and hippocampus [8].

The dysfunction of the cholinergic system plays an important role in the cognitive symptoms of dementia and normal aging. It is known that changes in other neurotransmitter systems such as NA, DA and serotonin may also cause these pathologies [10]. Loss of neuronal synapses and neuron death in $A D$ ultimately lead to a decrease in ACh and other neurotransmitters [4].

Although the peripheral effects of systemic senktide administration cannot be ignored, it has been reported that the results of the present study can be interpreted as the direct central effects of the drug, since there are many studies showing the brain penetration of systemically injected senktide [26].

\section{Behavioral and Memory Tests}

\section{Open Field Test}

OF test was performed at the beginning and at the end of the experiment to test the locomotor activities of the animals and to examine the anxiety levels. In the OF test distance moved, velocity and movement parameters were evaluated.

Last values were found to be decreased in all groups compared to the first measured values in distance, velocity and movement parameters which are important for locomotor activity.

Senktide had no effect on locomotor activity at doses of 0.1-0.4 mg/ $\mathrm{kg}$ alone [31]. In our study, it was thought that the decrease of locomotor activity may be sourced by the level of anxiety caused by the applications performed during the experiment. 
Anxiolytic, anxiogenic and antidepressant-like effects were observed of NK3R agonist and antagonist in OF and force swim tests. In the open field test, anxiolytic-like effect was observed with both low dose (0.2 $\mathrm{mg} / \mathrm{kg})$ and high dose $(0.4 \mathrm{mg} / \mathrm{kg})$ of senktide [20]. In another study, while NK2R agonism has memory loss and anxiogenic effects, NK3R agonists have been reported to show memory-healing and anxiolytic effects [25]. In our project the distance moved, velocity and movement were found to be reduced in the final measurement values. Different results between groups; showed that anxiety occurred in the AD group, senktide had anxiolytic effects and anxiolytic effects were reversed by antagonist administration.

\section{Morris's Water Maze Test}

Conflicting findings regarding learning and memory mechanism have been reported in NK3R damaged mice. Researchers found deficiencies in conditional avoidance and MWM tests [14]. In contrast, there was an improvement in operant task and spatial learning performance. This difference in the direction of the effect suggested that it may be due to the use of different genetic backgrounds used in the production of these animals [32]. Senktide has been found to alleviate scopolamine-induced dysfunction in its spatial working memory task [33]. An improvement was observed with senktide injection in MWM. This effect is completely blocked by pretreatment with an NK3R antagonist. NK3R antagonist itself did not affect learning and memory alone [21].

In our study, the parameters of the latency to platform, the distance moved, the velocity and the number of passes through the target quadrant were examined to evaluate the spatial memory in MWM.

While the shortest time to reach the platform at the testing stage in MWM is the $\mathrm{C}$ group, the longest is the $A D$ group. In the ADS group, the time to reach the platform was shortened by the effect of senktide. In the ADSO group, this effect returned with osanetant and the time was prolonged. Senktide has positive effects on learning. As the ADS group found the platform in a shorter time than the AD and ADSO groups, it was observed that senktide had positive effects on learning.

In the training phase of MWM, the distance moved parameter decreased in all groups for 4 consecutive days. The distance moved of the AD group during the test phase was the highest. The distance moved of the $C$ group and the ADS group was close to each other and less than the AD group. The fact that the distance moved parameter of the ADS group was lower than the AD group suggested that senktide had a curative effect on the learning deficits in $A D$.

In the MWM test, the number of passes through the target quadrant is a parameter that indicates the animals have learned the location of the platform and searched in that area. In the testing phase of the MWM, the number of passes through the target quadrant parameter of the ADS group was higher than the other groups. Although the results of the AD and ADSO groups were close to each other, the number of passing through the target quadrant was quite less than the other groups. This situation shows that the animals in the AD group cannot learn the target quadrant and that in the ADS group, senktide has an improving effect on learning deficits. The presence of similar findings in the ADSO group to the AD group suggested that the effects of senktide were dependent on NK3R. 
The fact that there was no difference in the velocity parameter in the MWM test suggested that there was no change in the locomotor activities of the animals between the groups. No difference in animal speeds means that velocity does not affect other results (latency to the platform, distance moved, number of passes through the target quadrant). The duration of the target quadrant in MWM indicates whether the animal has learned where is the platform. AD and ADSO groups are the groups that spend the least time in the quadrant where the platform is located. $C$ and $A D S$ groups spent close time in the target quadrant. With this parameter, it was observed that the ADS group showed a learning level close to the control group, and the animals in the AD and ADSO groups could not learn the target quadrant. The reversal of the positive effects of senktide with osanetant in the ADSO group suggested that senktide was dependent on NK3R. It is thought that the injection procedure may cause impairment in memory performance in the solvent-administered group. In this case, it has been stated that senktide supports memory by reducing the stress caused by the injection procedure [34]. Different results in the $\mathrm{C}$ and CS groups may be related to this.

\section{ELISA Analysis}

It has been determined that the activity of the cholinergic system can be stimulated by NK3R agonism in adult animals. Microdialysis results after systemic senktide administration showed that ACh levels increased in the frontal cortex, amygdala and hippocampus regions of aged rats. Low dose $(0.2 \mathrm{mg} / \mathrm{kg})$ was effective in increasing ACh levels in the frontal cortex and amygdala, and high dose $(0.4 \mathrm{mg} / \mathrm{kg}) \mathrm{was}$ effective in increasing ACh levels in the hippocampus [20]. The data indicate that the effects of senktide can be caused by changes in cholinergic neurotransmission.

NKB, the NK3R ligand, has been found to increase ACh levels in the hippocampus. No significant effect was seen in the frontal cortex. In the amygdala, there was an insignificant increase in ACh [25]. The pharmacological stimulation of NK3R has been shown to significantly improve learning and memory in older animals. These effects were most likely mediated by increased ACh levels in the major cholinergic projection target regions of the basal forebrain and the regulation of NK3R in the hippocampus. NK3R agonism also increased ACh activity in brain regions related to learning and memory. This effect is specific to NK3R because it is completely inhibited by NK3R antagonist [21].

Pharmacological inhibition of the metabolizing enzyme AChE has been shown to increase ACh levels and improve learning and memory in the aged organism. However, AChE inhibitors can have serious side effects in the peripheral and autonomic nervous system. NK3R agonists have a low effect on AChmediated peripheral mechanisms. Therefore, it is thought to be a way with a lower risk of side effects on brain ACh activity [9]. It has been reported that aging-related cholinergic neuron loss can be prevented by the endogenous NK3R agonist NKB [19]. In aged rats, subcutaneously administered senktide increased ACh in the hippocampus, amygdala and frontal cortex, and showed anxiolytic, promnestic effects [23].

In this study, the amount of AChE and ChAT was determined in the hippocampus and cortex tissues by ELISA method. While the amount of AChE in the hippocampus was increased in the AD and ADSO group, it was found to be lower in the ADS group than in these groups. On the contrary, the amount of 
hippocampal ChAT was lower in the AD and ADSO group, while it was increased in the ADS group. In other words, results consistent with our hypothesis were obtained in the amount of AChE and ChAT in the hippocampus tissue. Based on the knowledge that the systemic administration of NK3R agonists has a low effect on ACh-mediated peripheral mechanisms [21], it is thought that the extent of side effects may be safer.

\section{HPLC Analysis}

In $A D$, there is a progressive degeneration in the noradrenergic nuclei in the locus seruleus [35, 36]. It has been reported that noradrenergic innervation loss occurs in the cortex while the nigrostiatal DA system is not particularly affected in AD [37]. It has been reported that the memory enhancing effects of senktide can affect other neurotransmitter systems as well as the cholinergic system [27]. Low doses of NK3R agonist senktide have positive effects on temporal object recognition memory in rats with midbrain DA activity damage. This effect may be due to ACh release in the medial prefrontal cortex and hippocampus. Hemiparkinsonian model mice treated with $0.2 \mathrm{mg} / \mathrm{kg}$ senktide exhibited intact temporary temporal object recognition memory via the DA mechanism, unlike the control group [28].

According to the study data, the brain stem NA and DA concentration was lower in the AD group than in the other groups, while it was increased in the ADS group compared to AD group. It was thought that decreased catecholamine values in the AD group may be associated with impairment of cognitive functions and NK3R agonism can improve cognitive functions through catecholaminergic mechanisms.

\section{Conclusions}

$A D$ becomes a very important health problem with the increasing aged population. Therefore, researches for the diagnosis and treatment of $A D$ have become compulsory. Animal models are very helpful in clarifying $A D$ pathophysiology and discovering new pharmacotherapies. In experimental AD models, various learning and memory tests have been conducted for a long time. Various therapeutic agents can be tried to treat cognitive impairment in $A D$ through these models.

In this study, the findings of the MWM test, it was observed that the learning and memory mechanisms could be improved with NK3R agonist.Findings of hippocampal AChE and ChAT confirmed our hypothesis by supporting the positive effects of senktide on learning by mediating cholinergic mechanisms.

Considering that dementia is characteristic for normal aging and Alzheimer's disease, NK3R needs further investigation for possible pharmacological administrations in this type of cognitive decline. More effective treatment strategies can be developed for AD by making more scientific research in humans and animal models.

\section{Declarations}


Author Contributions: ZISG and ROK designed the study. ZISG, ROK, HS, AK and SK have made substantial contributions to the realization of experimental studies and to obtaining data. IK conducted ELISA analyses. SI has made the statistical analysis and interpretation of the study and has contributed to the creation of new software used for the study. ZISG and ROK have drafted the work and critically revised it for important intellectual content and approved its upcoming version. All authors approved the final version of the manuscript.

Compliance with Ethical Standards: This study protocol was approved by the Experimental Animals Local Ethics Committee of Necmettin Erbakan University Experimental Medicine Application and Research Center (No. 2016-050, 30.09.2016).

Conflict of interest: The authors declare that they have no potential conflicts of interest to disclosure.

Consent for Participate: Not applicable.

Consent for Publication: Not applicable.

Data Availability: The data sets supporting the conclusions of this article are included within the article. Data are however available from the authors upon reasonable request and with permission of (Third party name).

Funding: The study was supported by the Scientific Investigations Projects Coordinatorship of Necmettin Erbakan University (SIPC Project Number: 161418005).

\section{References}

1. Loera-Valencia R, Piras A, Ismail MAM, Manchanda S, Eyjolfsdottir H, Saido TC, Johansson J, Eriksdotter M, Winblad B, Nilsson P. Targeting Alzheimer's disease with gene and cell therapies. Journal of Internal Medicine. 2018; 28(1): 2-36. https://doi.org/10.1111/joim.12759

2. Bellozi PM, Lima IV, Doria JG, Vieira EL, Campos AC, Candelario-Jalil E, Reis HJ, Teixeira AL, Ribeiro FM, de Oliveira AC. Neuroprotective effects of the anticancer drug NVP-BEZ235 (dactolisib) on amyloid- $\beta$ 1-42 induced neurotoxicity and memory impairment. Scientific Reports. 2016; 6: 25226.https://doi.org/10.1038/srep25226

3. Kumar A, Singh A, Ekavali. A review on Alzheimer's disease pathophysiology and its management: an update. Pharmacological Reports. 2015; 67(2): 195-203.

https://doi.org/10.1016/j.pharep.2014.09.004

4. Chu LW. Alzheimer's disease: early diagnosis and treatment. Hong Kong Medical Journal. 2012; 18(3): 228-37. PMID: 22665688

5. Ballard C, Gauthier S, Corbett A, Brayne C, Aarsland D, Jones E. Alzheimer's disease. Lancet. 2011; 377(9770): 1019-31. https://doi.org/10.1016/S0140-6736(10)61349-9 
6. Mesulam MM. Aging, Alzheimer's Disease and Dementia: Clinical and Neurobiological Perspectives. In: M.-Marsel Mesulam (ed): Principles of Behavioral and Cognitive Neurology, New York, Oxford University Press 2000; 2: 432-529.

7. Bartus RT. On neurodegenerative diseases, models, and treatment strategies: lessons learned and lessons forgotten a generation following the cholinergic hypothesis. Experimental Neurology. 2000; 163(2): 495-529. https://doi.org/10.1006/exnr.2000.7397

8. Mesulam MM. The cholinergic lesion of Alzheimer's disease: pivotal factor or side show? Learning and Memory. 2004; 11(1): 43-9. https://doi.org/10.1101/Im.69204

9. Pinz MP, Dos Reis AS, Vogt AG, Krüger R, Alves D, Jesse CR, Roman SS, Soares MP, Wilhelm EA, Luchese C. Current advances of pharmacological properties of 7-chloro-4-(phenylselanyl) quinoline: Prevention of cognitive deficit and anxiety in Alzheimer's disease model. Biomedicine Pharmacotherapy. 2018; 105:1006-1014. https://doi.org/10.1016/j.biopha.2018.06.049

10. Garibotto V, Tettamanti M, Marcone A, Florea I, Panzacchi A, Moresco R, Virta JR, Rinne J, Cappa SF, Perani D. Cholinergic activity correlates with reserve proxies in Alzheimer's disease. Neurobiology of Aging. 2013; 34(11): 2694, 3-8. https://doi.org/10.1016/j.neurobiolaging.2013.05.020

11. Severini C, Improta G, Falconieri-Erspamer G, Salvadori S, Erspamer V. The tachykinin peptide family. Pharmacological Reviews. 2002; 54(2): 285-322. https://doi.org/10.1124/pr.54.2.285

12. Nagano M, Saitow F, Haneda E, Konishi S, Hayashi M, Suzuki H. Distribution and pharmacological characterization of primate NK-1 and NK-3 tachykinin receptors in the central nervous system of the rhesus monkey. British Journal of Pharmacology. 2006; 147(3): 316-23.

https://doi.org/10.1016/j.neulet.2011.07.057

13. Linari G, Broccardo M, Nucerito V, Improta G. Selective tachykinin NK3-receptor agonists stimulate in vitro exocrine pancreatic secretion in the guinea pig. Peptides. 2002; 23(5): 947-53. https://doi.org/10.1016/s0196-9781(02)00010-4

14. Siuciak JA, McCarthy SA, Martin AN, Chapin DS, Stock J, Nadeau DM, Kantesaria S, Bryce-Pritt D, McLean S. Disruption of the neurokinin-3 receptor (NK3) in mice leads to cognitive deficits. Psychopharmacology. 2007; 194, 185-195. https://doi.org/10.1007/s00213-007-0828-6

15. Duarte CR, Schütz $B$, Zimmer A. Incongruent pattern of neurokinin $B$ expression in rat and mouse brains. Cell and Tissue Research. 2006; 323(1): 43-51. https://doi.org/10.1007/s00441-005-0027-x

16. Chen LW, Wei LC, Liu HL, Ding YQ, Zhang H, Rao ZR, Ju G, Chan YS. Cholinergic neurons expressing neuromedin $\mathrm{K}$ receptor (NK3) in the basal forebrain of the rat: A double immunofluorescence study. Neuroscience. 2001a; 103, 413-422. https://doi.org/10.1016/s0306-4522(00)00568-6

17. Morozova E, Wu M, Dumalska I, Alreja M. Neurokinins robustly activate the majority of septohippocampal cholinergic neurons. European Journal of Neuroscience. 2008; 27, 114-122. https://doi.org/10.1111/j.1460-9568.2007.05993.x

18. Arenas E, Alberch J, Perez-Navarro E, Solsona C, Marsal J. Neurokinin receptors differentially mediate endogenous acetylcholine release evoked by tachykinins in the neostriatum. Journal of Neuroscience. 1991; 11, 2332-2338. https://doi.org/10.1523/JNEUROSCl.11-08-02332.1991

Page 15/35 
19. Wenk GL, Zajaczkowski W, Danysz W. Neuroprotection of acetylcholinergic basal forebrain neurons by memantine and neurokinin B. Behavioural Brain Research. 1997; 83, 129-133. https://doi.org/10.1016/s0166-4328(97)86056-1

20. Schable S, Topic B, Buddenberg T, Petri D, Huston JP, De Souza Silva MA. Neurokinin(3)-R agonism in aged rats has anxiolytic-, antidepressant-, and promnestic-like effects and stimulates ACh release in frontal cortex, amygdala and hippocampus. European Neuropsychopharmacology. 2011; 21(6), 484494. https://doi.org/10.1016/j.euroneuro.2010.11.010

21. De Souza Silva MA, Lenz B, Rotter A, Biermann T, Peters O, Ramirez A, Jessen F, Maier W, Hüll M, Schröder J, Frölich L, Teipel S, Gruber O, Kornhuber J, Huston JP, Müller CP, Schable S. Neurokinin3 receptor as a target to predict and improve learning and memory in the aged organism. Proceedings of the National Academy of Sciences of the United States of America. 2013; 110(37): 15097-102. https://doi.org/10.1073/pnas.1306884110

22. De Souza Silva MA, Hasenohrl RU, Tomaz C, Schwarting RK, Huston JP. Differential modulation of frontal cortex acetylcholine by injection of substance $\mathrm{P}$ into the nucleus basalis magnocellularis region in the freelymoving vs. the anesthetized preparation. Synapse. 2000; 38, 243-253. https://doi.org/10.1002/1098-2396(20001201)38:3

23. Schable S, Huston JP, Brandao ML, Dere E, De Souza Silva MA. Neurokinin-2 receptor antagonism in medial septum influences temporal-order memory for objects and forebrain cholinergic activity. Peptides. 2010; 31:108-115. https://doi.org/10.1016/j.peptides.2009.10.009

24. Ribeiro SJ, Teixeira RM, Calixto JB, De Lima TC. Tachykinin NK(3)receptor involvement in anxiety. Neuropeptides. 1999; 33:181-188. https://doi.org/10.1054/npep.1999.0021

25. Schable S, Huston JP, Silva MA. Neurokinin2-R in medial septum regulate hippocampal and amygdalar ACh release induced by intraseptal application of neurokinins A and B. Hippocampus. 2012b; 22(5): 1058-67. https://doi.org/10.1002/hipo.20847

26. Zlomuzica A, Dere E, Huston JP, De Souza Silva MA. NK(3) receptor agonism promotes episodic-like memory in mice. Neurobiology of Learning and Memory. 2008; 90(2): 420-5. https://doi.org/10.1016/j.nlm.2008.04.013

27. Chao OY, Nikolaus S, Huston JP, De Souza Silva MA. The neurokinin-3 receptor agonist senktide facilitates the integration of memories for object, place and temporal order into episodic memory. Neurobiology of Learning and Memory. 2014; 114: 178-85. DOI: https://doi.org/10.1016/j.nlm.2014.06.009

28. Chao OY, Wang AL, Nikolaus S, De Souza Silva MA. NK3 receptor agonism reinstates temporal order memory in the hemiparkinsonian rat. Behavioural Brain Research. 2015; 285: 208-12. https://doi.org/10.1016/j.bbr.2014.06.006

29. Sahin Z, Solak H, Koç A, Ozen Koca R, Ozkurkculer A, Çakan P, Solak Gormus ZI, Kutlu S \& Kelestimur $H$ (2018). Long-term metabolic cage housing increases anxiety/depression-related behaviours in adult male rats. Archieves of Physiology and Biochemistry ISSN: 1381-3455. https://doi.org/10.1080/13813455.2018.1441314 
30. Sahin Z, Ozkurkculer A, Kalkan OF, Ozkaya A, Koc A, Ozen Koca R, Solak H, Solak Gormus ZI, Kutlu S (2020). Chronic immobilization stress induces anxiety-related behaviors and affects brain essential minerals in male rats. International Journal for Vitamin and Nutrition Research, pp 1-8. https://doi.org/10.1024/0300-9831/a000682

31. De Souza Silva MA, Mello EL Jr, Müller CP, Jocham G, Maior RS, Huston JP, Tomaz C, Barros M. Interaction of the tachykinin NK3 receptor agonist senktide with behavioral effects of cocaine in marmosets (Callithrix penicillata). Peptides. 2006; 27(9): 2214-23.

https://doi.org/10.1016/j.peptides.2006.03.005

32. Nordquist RE, Delenclos M, Ballard TM, Savignac H, Pauly-Evers M, Ozmen L, Spooren W. Cognitive performance in neurokinin 3 receptor knockout mice. Psychopharmacology. 2008; 198, 211-220. https://doi.org/10.1007/s00213-008-1119-6

33. Kameyama T, Ukai M, Shinkai N. Ameliorative effects of tachykinins on scopolamine-induced impairment of spontaneous alternation performance in mice. Methods and Findings in Experimental and Clinical Pharmacology. 1998; 20, 555-560. https://doi.org/10.1358/mf.1998.20.7.485718

34. Kart-Teke E, Dere E, Brandao ML, Huston JP, De Souza Silva MA. Reinstatement of episodic-like memory in rats by neurokinin-1 receptor antagonism. Neurobiology of Learning and Memory. 2007; 87(3): 324-31. https://doi.org/10.1016/j.nlm.2006.09.007

35. Heneka MT, Nadrigny F, Regen T, Martinez-Hernandez A, Dumitrescu-Ozimek L, Terwel D, JardanhaziKurutz D, Walter J, Kirchhoff F, Hanisch UK, Kummer MP. Locus ceruleus controls Alzheimer's disease pathology by modulating microglial functions throughnorepinephrine. Proceedings of the National Academy of Sciences of the United States of America. 2010; 107(13): 6058-63. https://doi.org/10.1073/pnas.0909586107

36. Trillo L, Das D, Hsieh W, Medina B, MoghadaM S, Lin B, Dang V, Sanchez MM, De Miquel Z, Ashford JW, Salehi A. Ascending monoaminergic systems alterations in Alzheimer's disease. Translating basic science into clinical care. Neuroscience \& Biobehavioral Reviews. 2013; 37 (8): 1363-79. https://doi.org/10.1016/j.neubiorev.2013.05.008

37. Hirao K, Pontone GM, Smith GS. Molecular imaging of neuropsychiatric symptoms in Alzheimer's and parkinson's disease. Neuroscience \& Biobehavioral Reviews. 2015; 49C: 157-170. https://doi.org/10.1016/j.neubiorev.2014.11.010

\section{Tables}

Table 1 Distance moved parameters in the OF test $(\mathrm{cm})$ 


\begin{tabular}{|llllll|} 
AM \pm SE & C & AD & ADS & ADSO & CS \\
\hline 1. & $1330.8 \pm 180.4$ & $1325.6 \pm 190.2$ & $1506.2 \pm 190.2$ & $1801.8 \pm 180.4$ & $2041.4 \pm 180.4$ \\
\hline 2. & $522.9 \pm 180.48$ & $740.8 \pm 190.24$ & $638.5 \pm 190.24$ & $460.9 \pm 180.48$ & $582.2 \pm 180.48$ \\
\hline
\end{tabular}

Table 2 Velocity of groups in OF test $(\mathrm{cm} / \mathrm{s})$

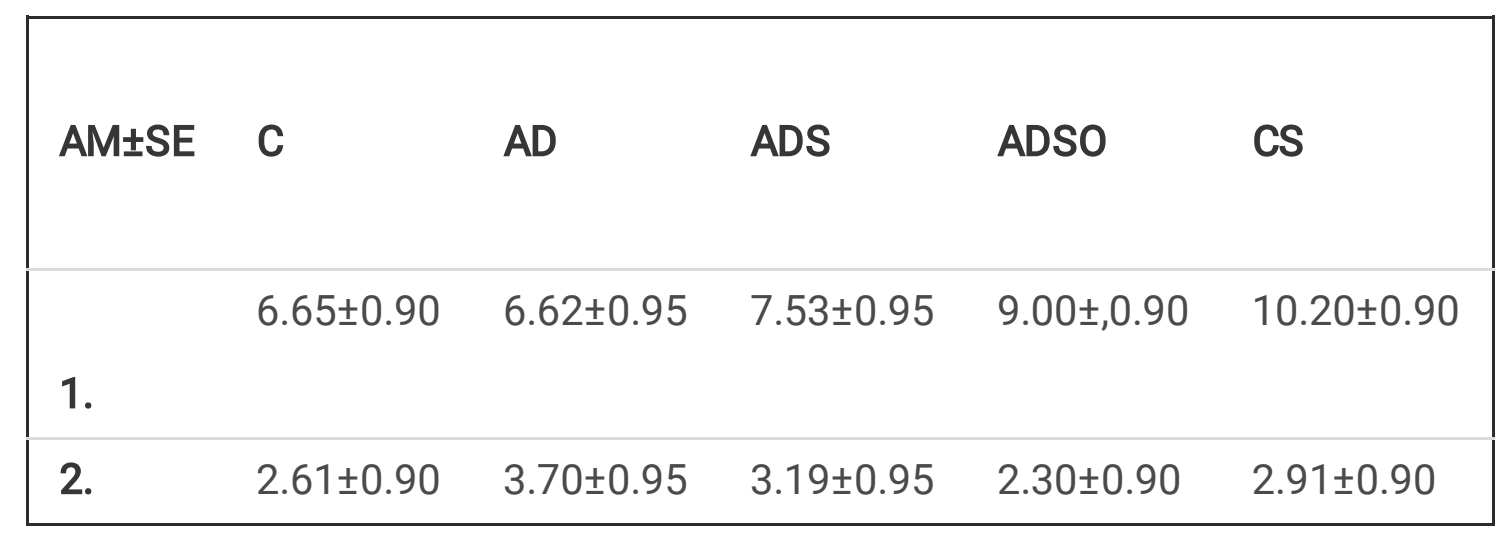

Table 3 Movement percentages in OF test (\%)

\begin{tabular}{|llllll|}
\hline AM \pm SE & C & AD & ADS & ADSO & CS \\
& & & & & \\
& $2.59 \pm 0.27$ & $2.82 \pm 0.29$ & $3.14 \pm 0.29$ & $3.26 \pm 0.27$ & $2.79 \pm 0.27$ \\
1. & & & & & \\
\hline 2. & $1.48 \pm 0.27$ & $1.95 \pm 0.29$ & $1.75 \pm 0.29$ & $1.20 \pm 0.27$ & $1.56 \pm 0.27$ \\
& & & & & \\
\hline
\end{tabular}

Table 4 Latency to the platform in the MWM test (s) 


\begin{tabular}{llllll|} 
ORT \pm SH & K & AH & AHS & AHSO & KS \\
\hline 5. gün & $9.40 \pm 6.12$ & $34.25 \pm 7.49$ & $25.85 \pm 6.12$ & $33.05 \pm 7.49$ & $21.90 \pm 5.66$ \\
\hline
\end{tabular}

Table 5 The distance moved by the groups in the MWM test $(\mathrm{cm})$

\begin{tabular}{|llllll|}
\hline AM \pm SE & C & AD & ADS & ADSO & CS \\
\hline Test & $5749.62 \pm 652.5$ & $10387 \pm 687.81$ & $6586.84 \pm 729.5$ & $1481.40 \pm 652.5$ & $1538.89 \pm 652.5$ \\
\hline
\end{tabular}

Table 6 The number of passes through the target quadrant during the test phase of the groups in the MWM test

$\begin{array}{llllll}\text { AM } \pm S E & \text { C } & \text { AD } & \text { ADS } & \text { ADSO } & \text { CS } \\ & & & & & \\ \text { Test } & 20.00 \pm 3.32 & 8.66 \pm 3.50 & 32.75 \pm 3.71 & 6.60 \pm 3.32 & 28.70 \pm 3.32\end{array}$

Table 7 The time spent of the groups in the target quadrant of the MWM test (s)

\begin{tabular}{llllll|} 
AM \pm SE & C & AD & ADS & ADSO & CS \\
& & & & & \\
\hline Test & $22.61 \pm 1.81$ & $15.38 \pm 1.90$ & $22.90 \pm 2.02$ & $17.10 \pm 1.81$ & $25.50 \pm 1.81$ \\
\hline
\end{tabular}


Table 8 AChE amount in hippocampus and cortex tissues (pg/mg protein)

\begin{tabular}{|llllll|}
\hline AM \pm SE & C & AD & ADS & ADSO & CS \\
\hline AChEcrx & $56,62 \pm 2,06$ & $41,42 \pm 2,17$ & $37,93 \pm 2,30$ & $35,23 \pm 2,06$ & $35,82 \pm 2,06$ \\
\hline AChEhpc & $41,16 \pm 2,06$ & $45,93 \pm 2,17$ & $42,38 \pm 2,30$ & $46,3 \pm 2,06$ & $33,61 \pm 2,06$ \\
\hline
\end{tabular}

Table 9 The amount of ChAT amount ( $\mathrm{ng} / \mathrm{mg}$ protein) in hippocampus and cortex tissues

\begin{tabular}{|llllll|}
\hline AM \pm SE & C & AD & ADS & ADSO & CS \\
\hline CHATcrx & $0,23 \pm 0,008$ & $0,32 \pm 0,008$ & $0,26 \pm 0,009$ & $0,33 \pm 0,008$ & $0,29 \pm 0,008$ \\
\hline CHAThpc & $0,33 \pm 0,008$ & $0,27 \pm 0,008$ & $0,35 \pm 0,009$ & $0,30 \pm 0,008$ & $0,32 \pm 0,008$ \\
& & & & & \\
\hline
\end{tabular}

Table 10 Catecholamines in brainstem (pg amine/mg tissue)

\begin{tabular}{|lllllll|}
\hline AM \pm SE & C & AD & ADS & ADSO & CS & P \\
\hline NA & $143.66 \pm 20.8$ & $110.93 \pm 22.1$ & $120.14 \pm 23.6$ & $141.16 \pm 20.8$ & $159.80 \pm 20.8$ & 0.5293 \\
\hline DA & $43.11 \pm 5.81$ & $13.69 \pm 6.16$ & $25.60 \pm 6.59$ & $59.26 \pm 5.81$ & $28.10 \pm 5.81$ & $<.0001$ \\
\hline
\end{tabular}




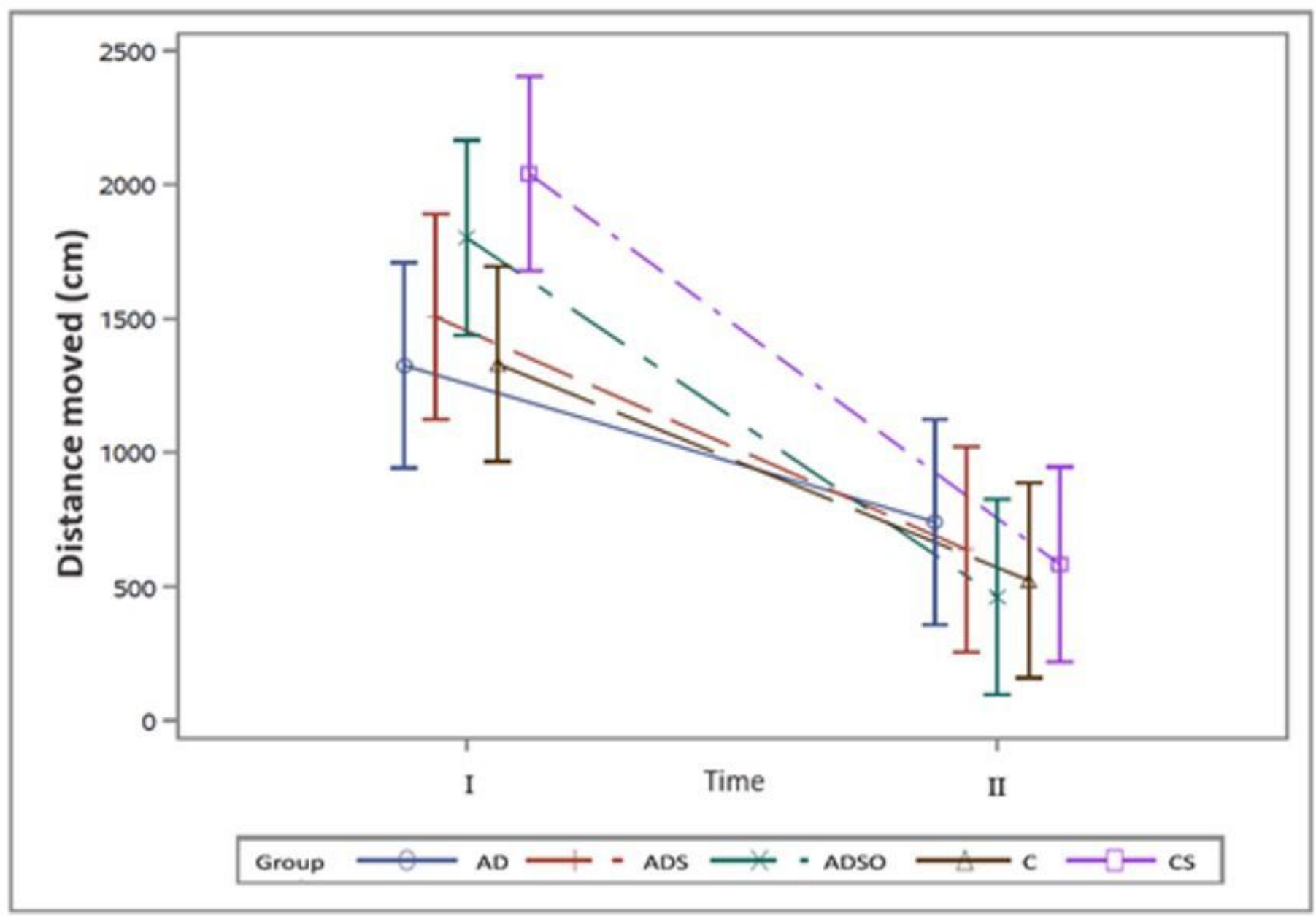

Figure 1

Distance moved parameters in the OF test. The difference between the groups was not statistically significant $(p=0.4185)(p>0.05)$. When the two distance moved values were compared in the experiment, the second distance moved parameters were lower in all groups $(p<0.05)$. 


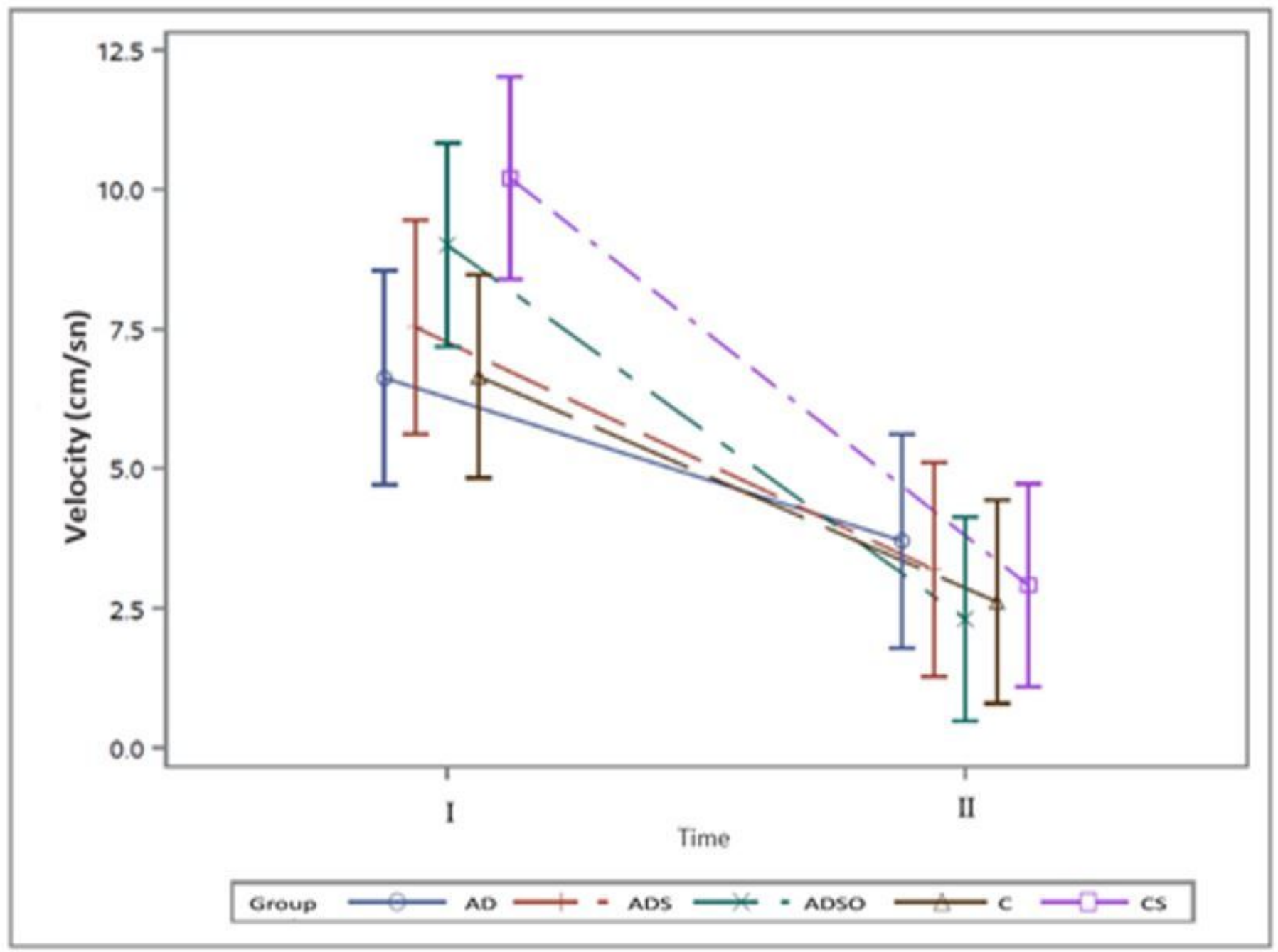

Figure 2

In the open field test, the velocity parameter was found to be significant in terms of time and group time interaction $(p<0.05)$. When two measurement values were compared in the experiment, the velocity was lower on the second measurements in all groups $(p<0.05)$. 


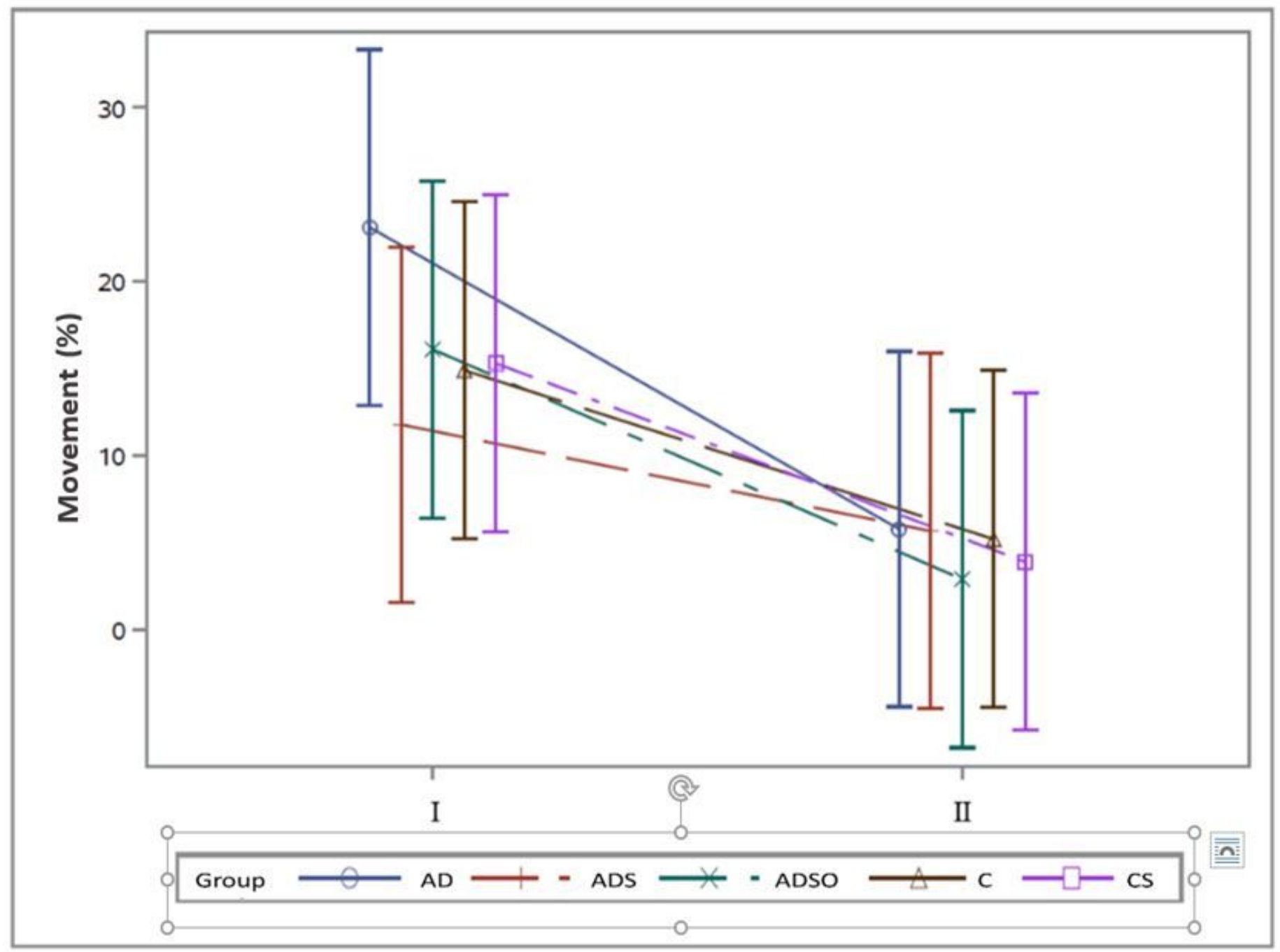

Figure 3

In the open field test, the percentage of movement was found to be significantly different between two values $(p<0.05)$. Percentages of movement were lower in all groups at the end of the experiment. There was no significant difference between the groups $(p=0.7501)$. 


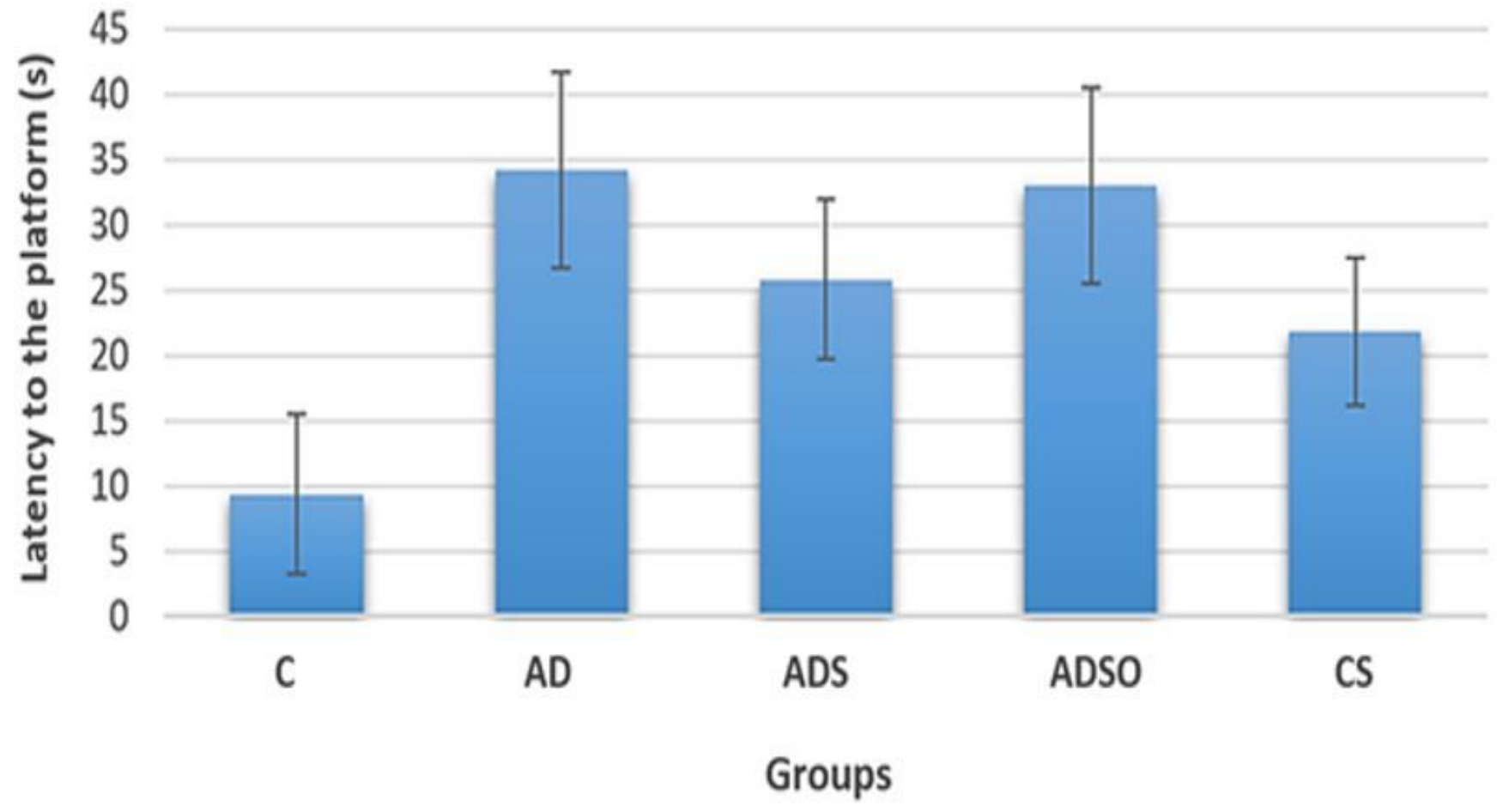

Figure 4

No significant difference was found for the group effect in the latency to the platform on the MWM test phase $(p=0.0908)$. 


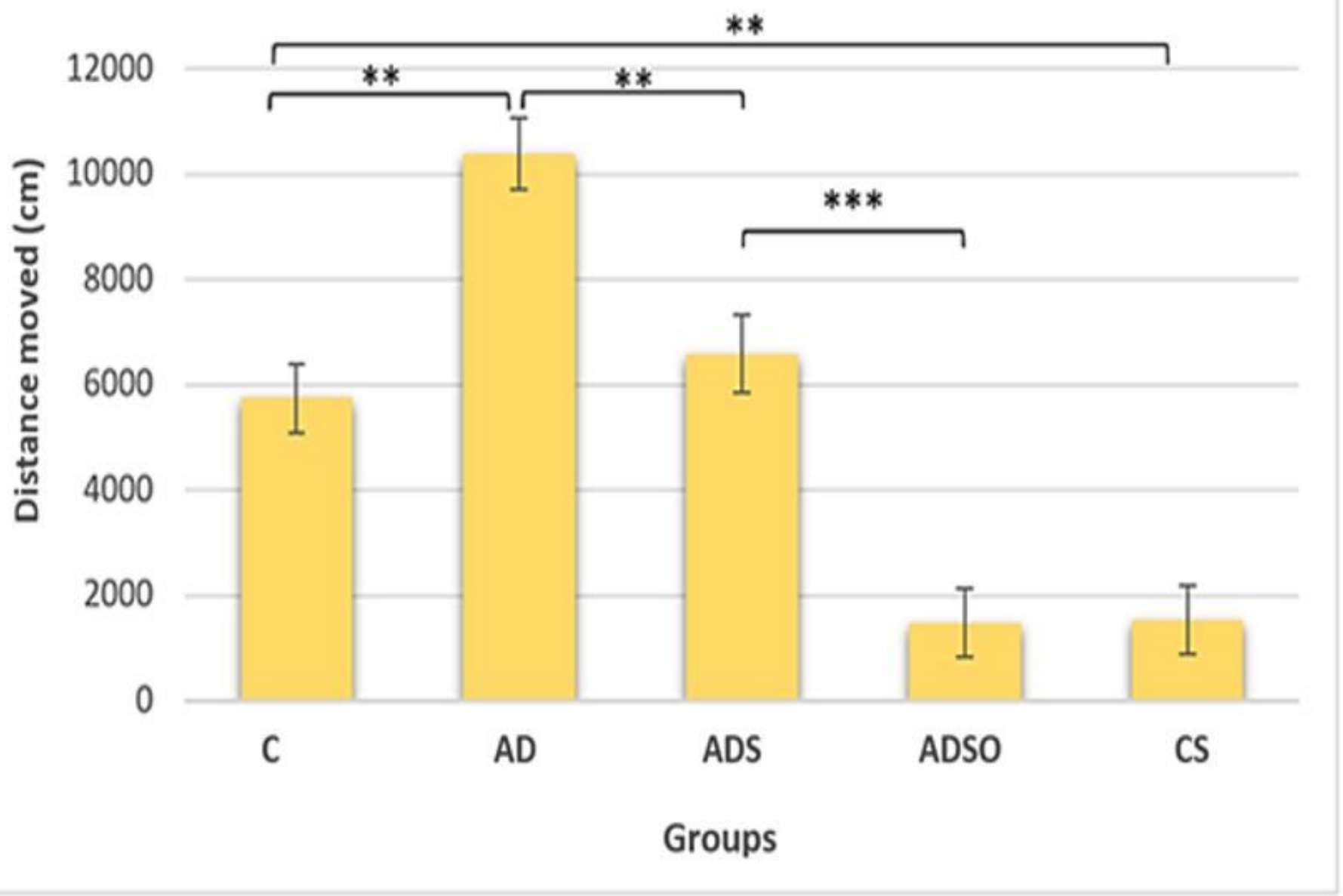

Figure 5

A significant difference was found between the groups in the distance moved parameter during the MWM test phase $(* \star: p<0.01)(* \star *: p<0.0001)$. 

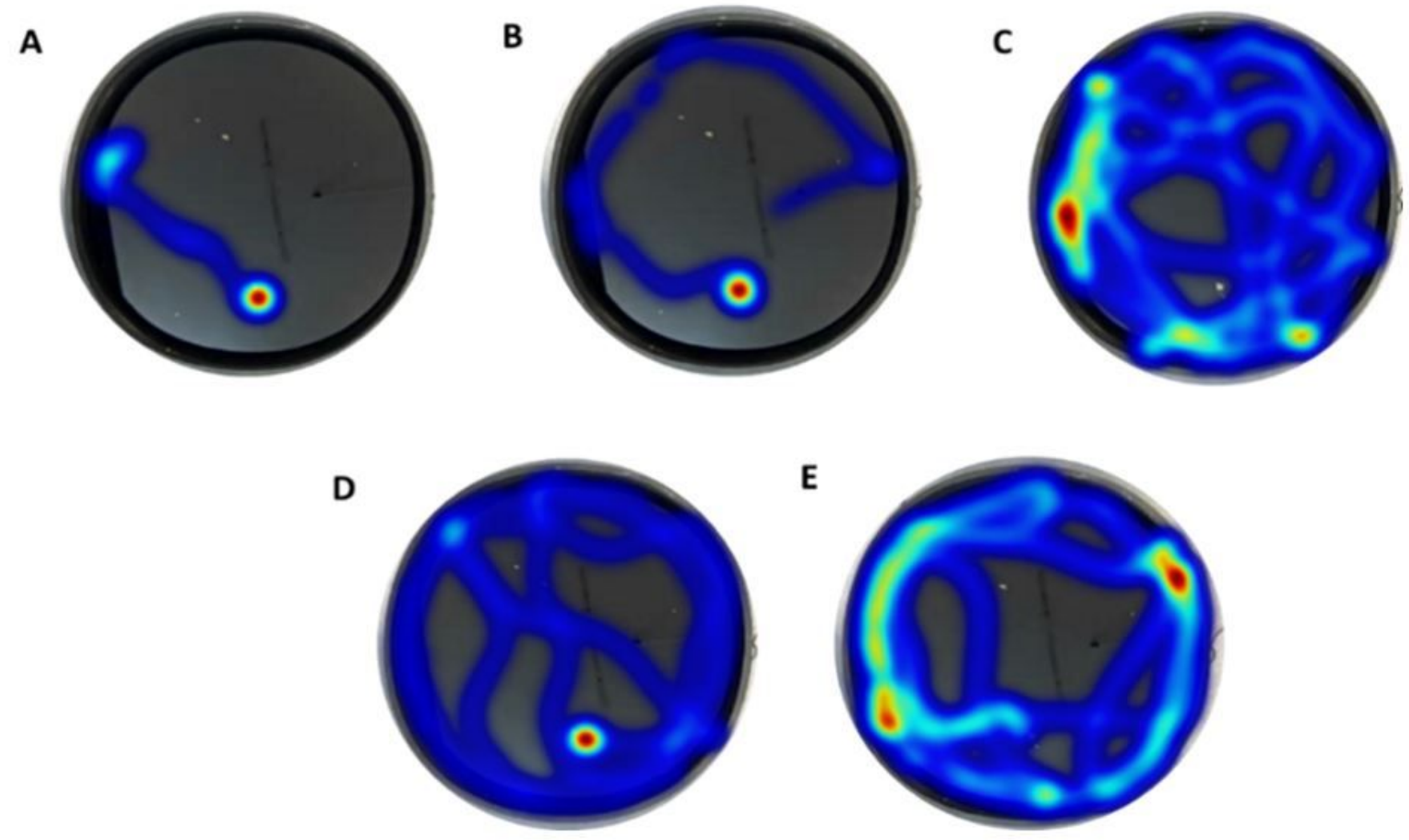

\section{Figure 6}

Heatmap of MWM test in Ethovision software program (A: C group, B: CS group, C: AD group, D: ADS group, E: ADSO group) 
A

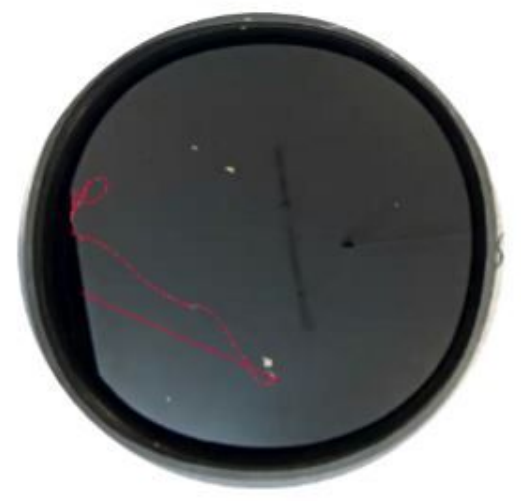

B

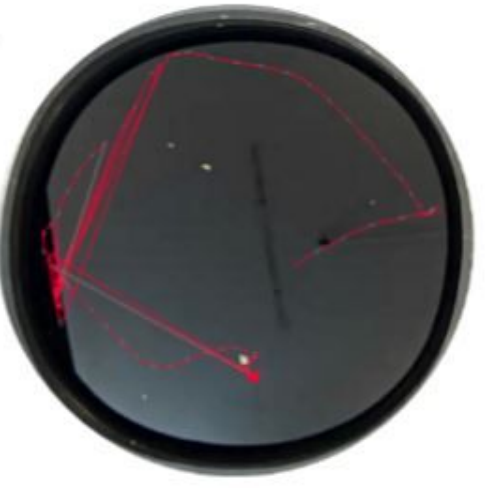

C

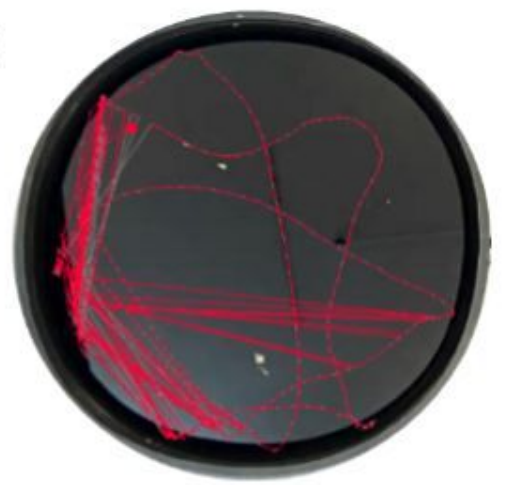

D

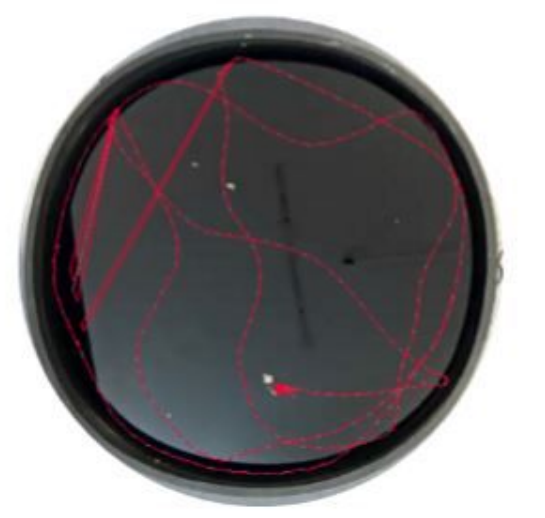

$\mathbf{E}$

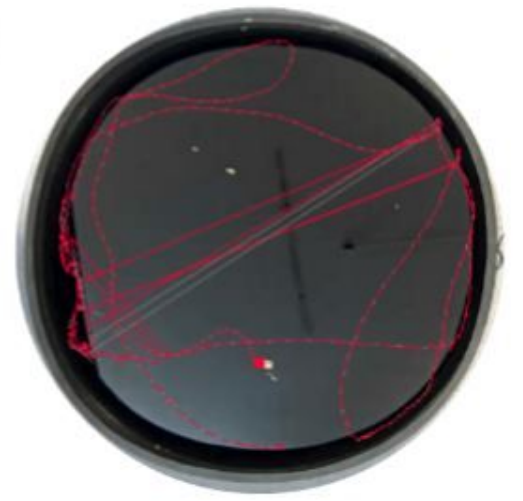

Figure 7

Roadmap of MWM test in Ethovision software program (A: C group, B: CS group, C: AD group, D: ADS group, E: ADSO group) 


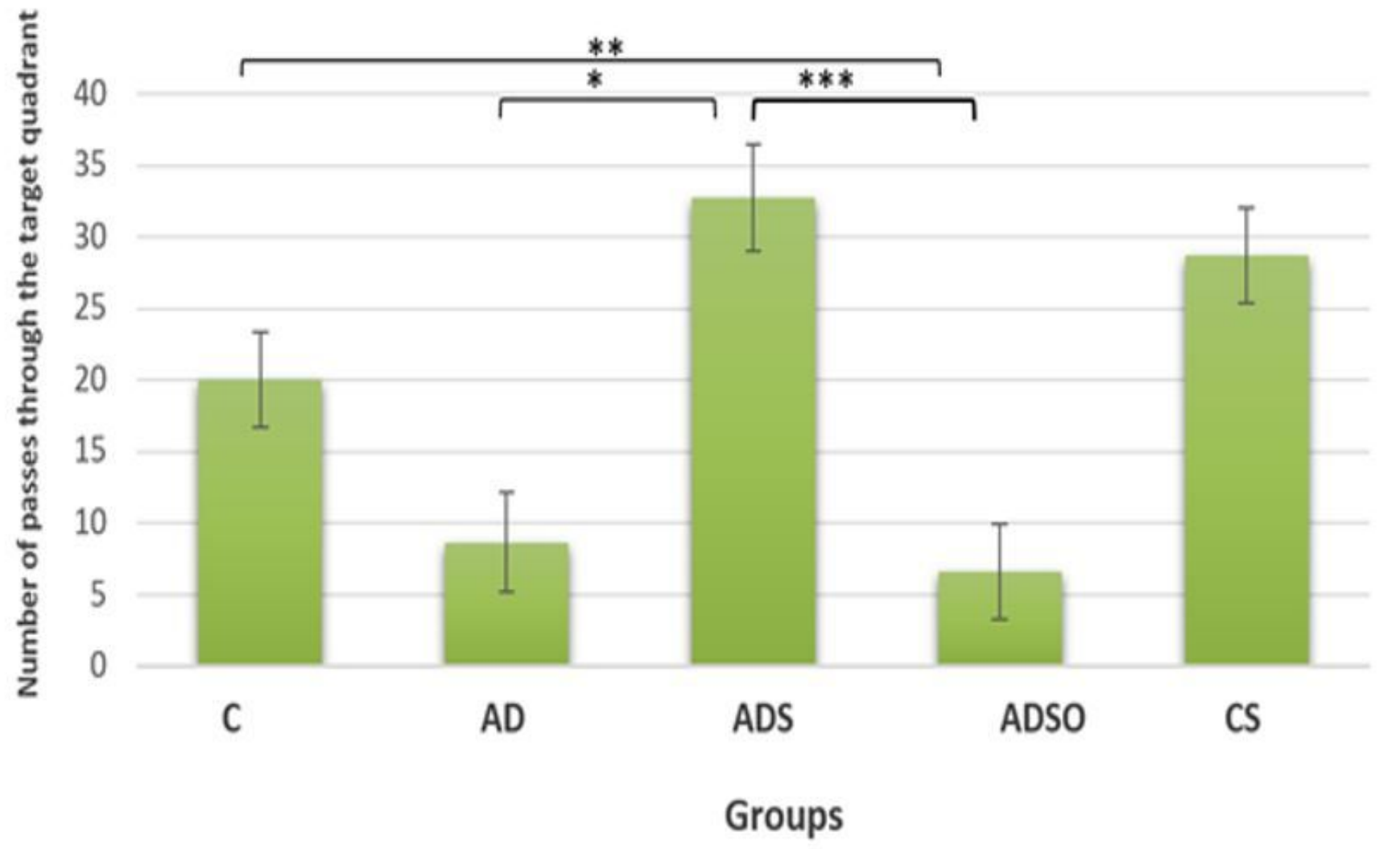

Figure 8

In the MWM test phase, a significant difference was found between the groups in the parameter of the number of passes through the target quadrant $(*: p<0.05)(* *: p<0.01)(* \star *: p<0.0001)$. 


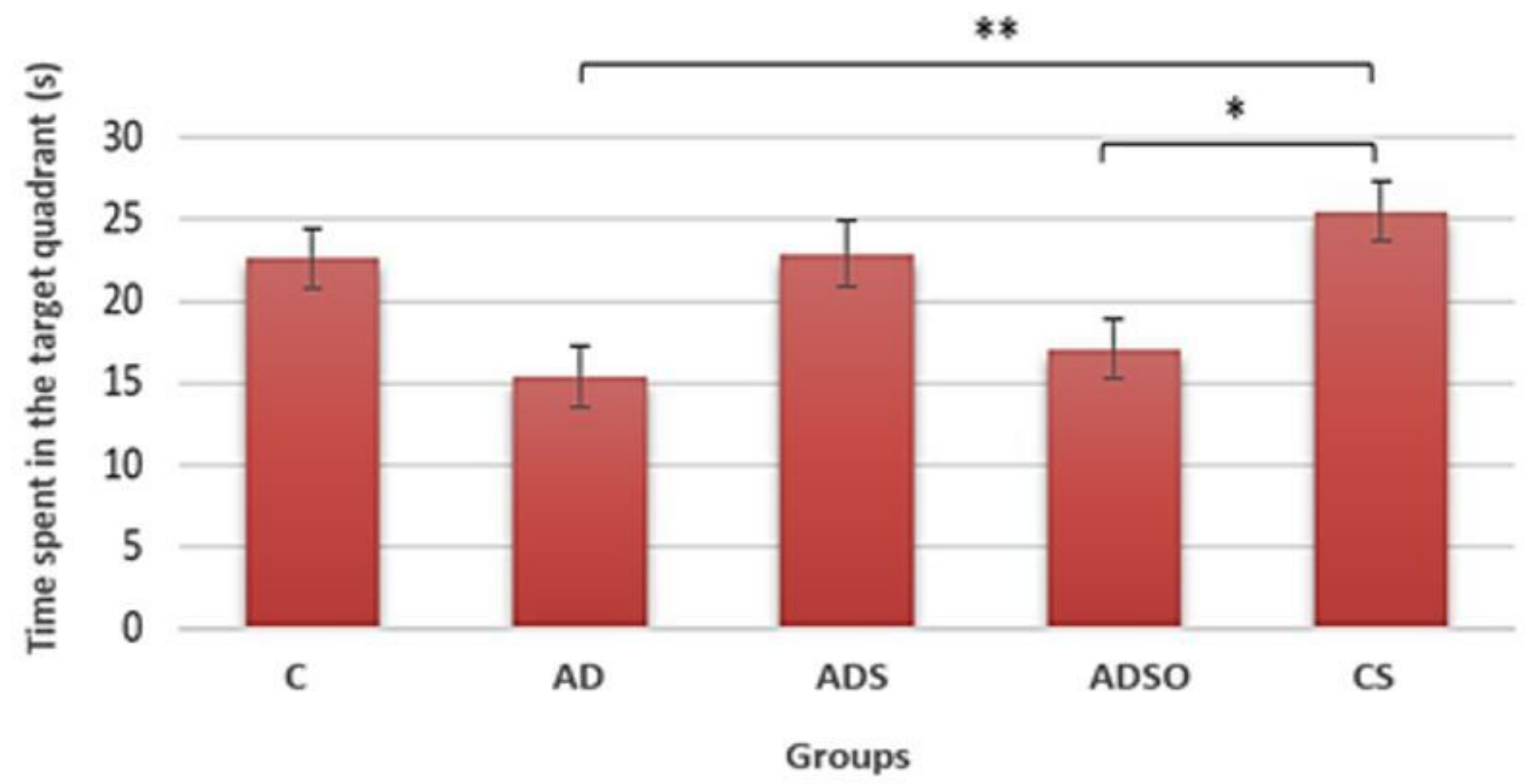

Figure 9

In the MWM test phase, a significant difference was found between the groups in the parameter of the time spent in the target quadrant. The durations of AD and ADSO groups in the target quadrant were significantly lower than the CS group ( $*$ : $<0.05, * \star$ : $p<0.01)$. 


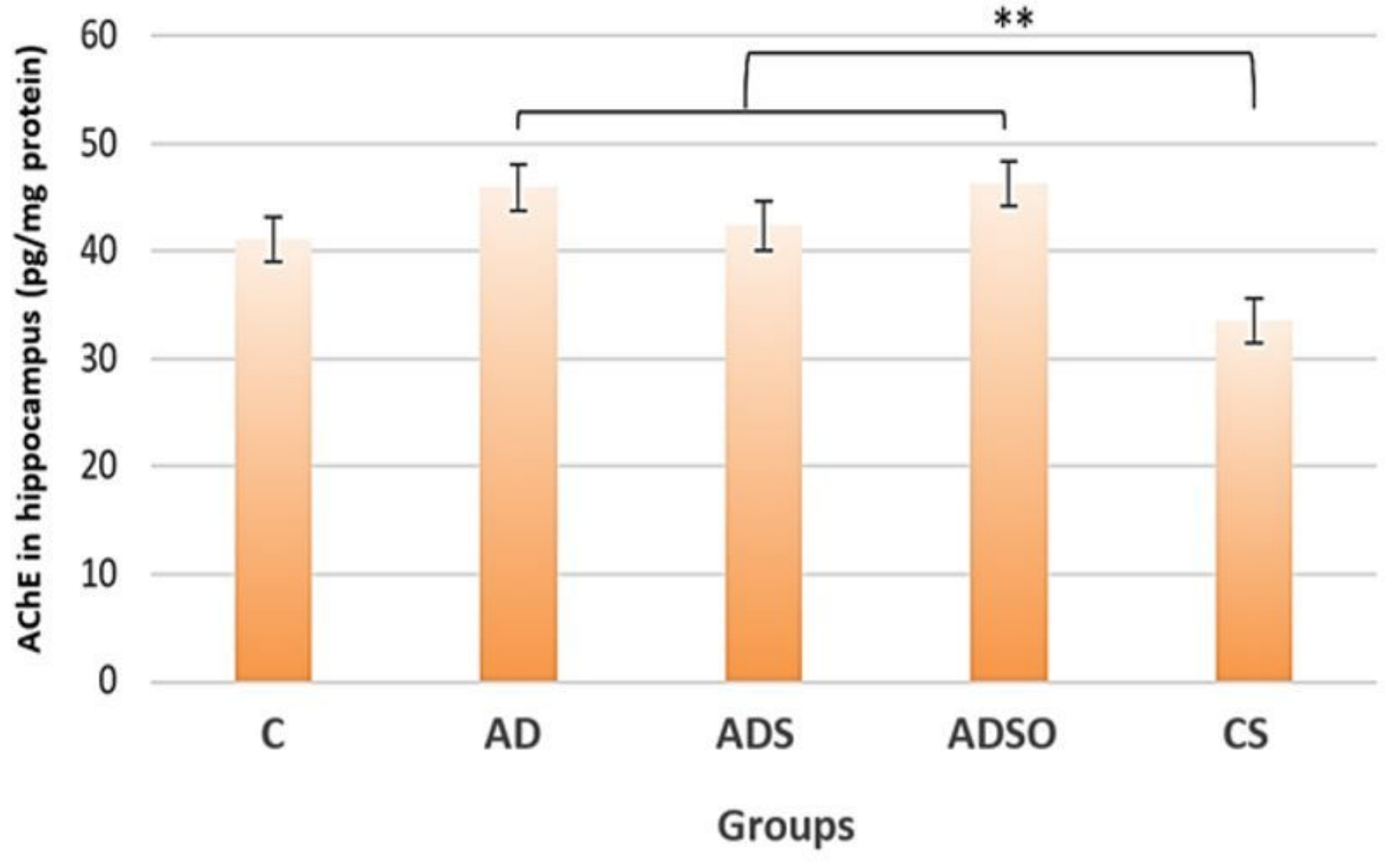

Figure 10

The amount of AChE in the hippocampus tissue was found to be significantly different between groups and in group tissue interaction $(p<0.0001)$. A statistically significant difference was found between the CS group and the AD and ADSO groups $(p=0.0008)(* *: p<0.01)$. 


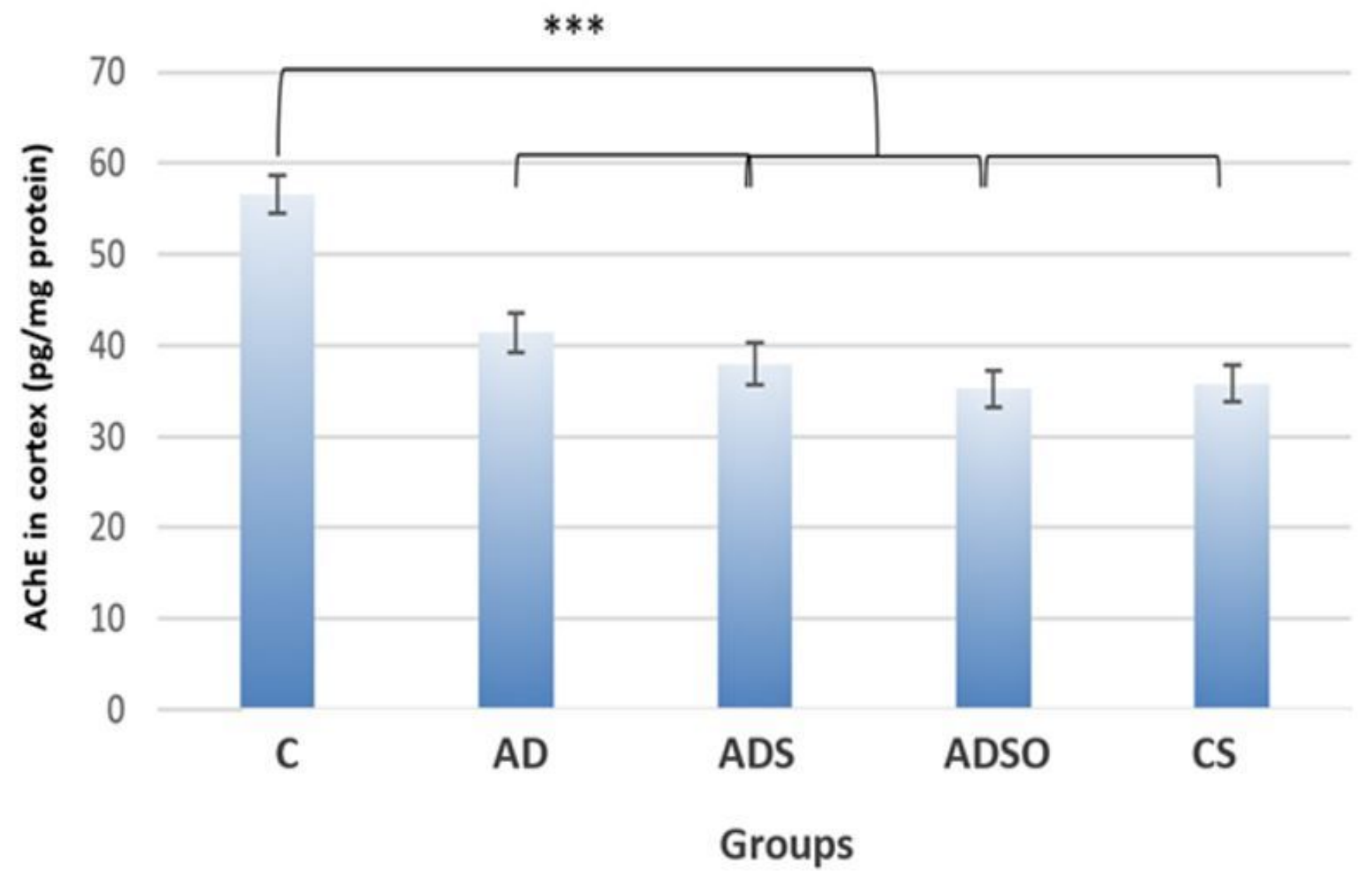

Figure 11

The amount of $A C h E$ in cortex tissue was found to be significantly different between groups and in group tissue interaction $(p<0.0001)$. A statistically significant difference was observed between the $C$ group and all groups in the cortex tissue ( $\left.{ }^{\star * \star}: p<0.0001\right)$. 


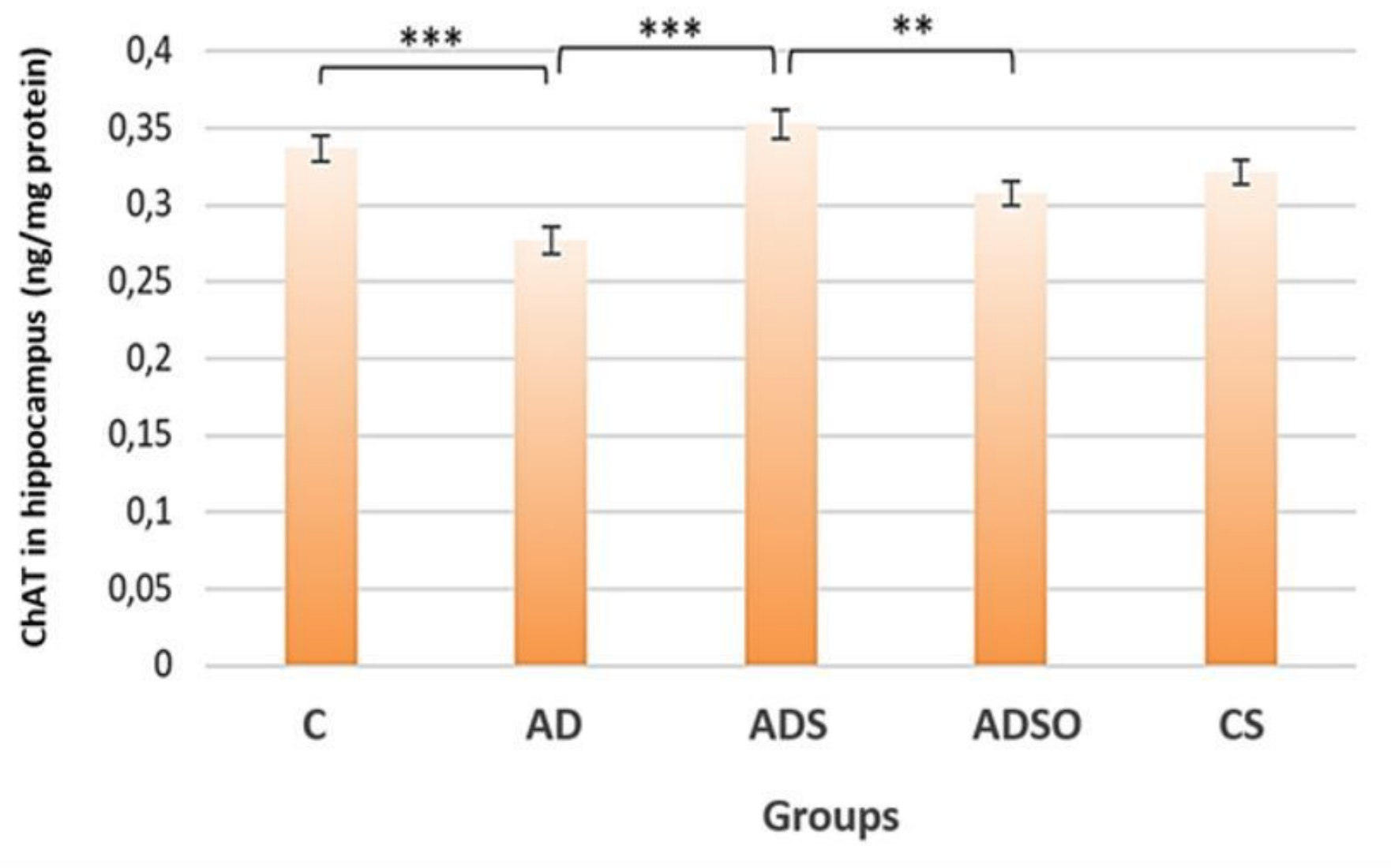

Figure 12

The amount of ChAT in the hippocampus tissue was found to be significantly different between groups, between tissues and in group-tissue interaction. A statistically significant difference was found between the AD group and the ADS and C groups $(p<0.0001)$, and between the ADS group and the ADSO group (**: $p<0.01, \star \star \star: p<0.0001)$. 


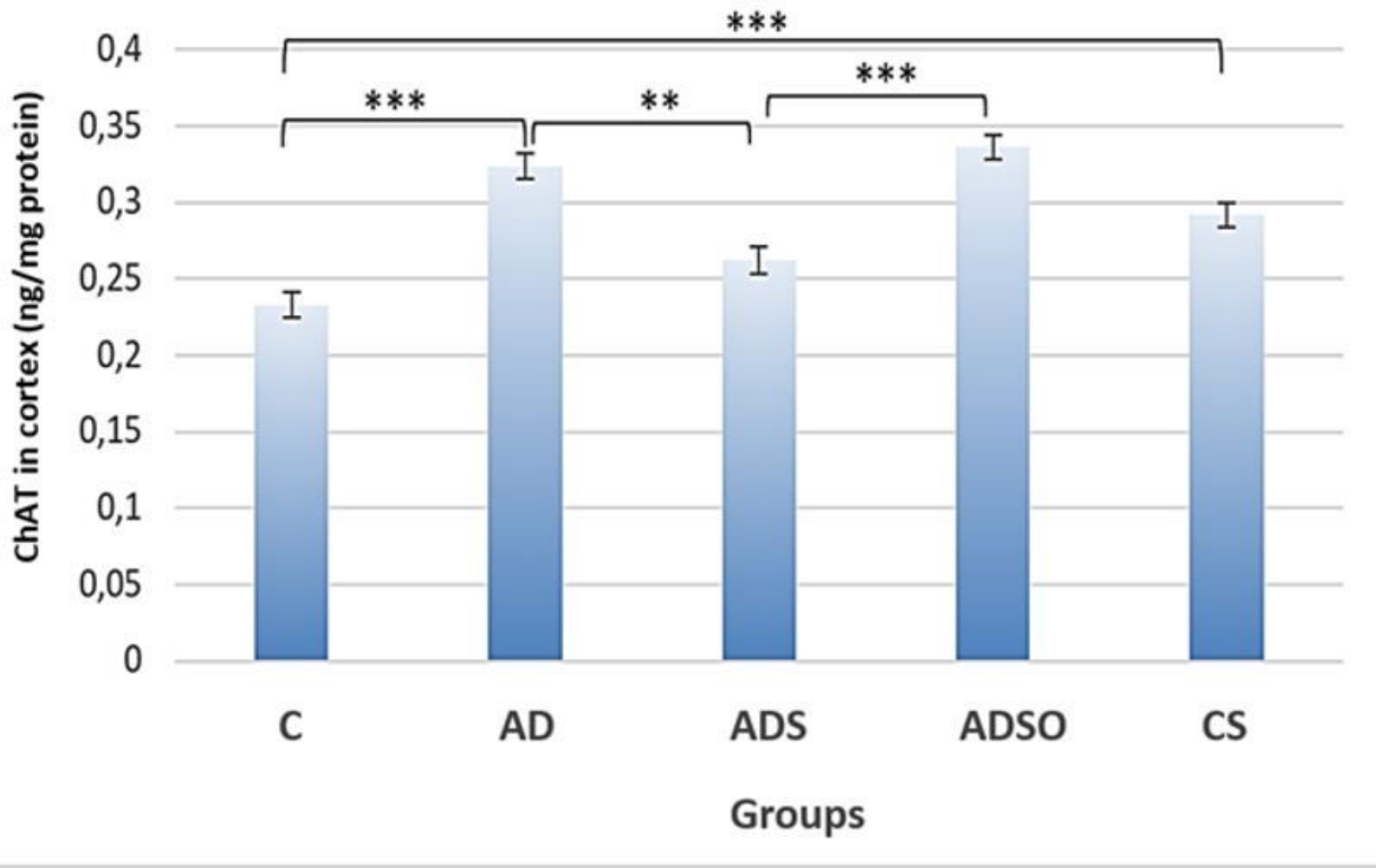

Figure 13

The amount of ChAT in cortex tissue was found to be significantly different between groups, between tissues and in group tissue interaction. A statistically significant difference was observed between the AD group and the ADS group and the $C$ group, between the ADS group and the ADSO group, between the ADSO group and the $C$ group, and between the $C$ group and the CS group (**: $p<0.01, \star \star *$ : $p<0.0001$ ). 


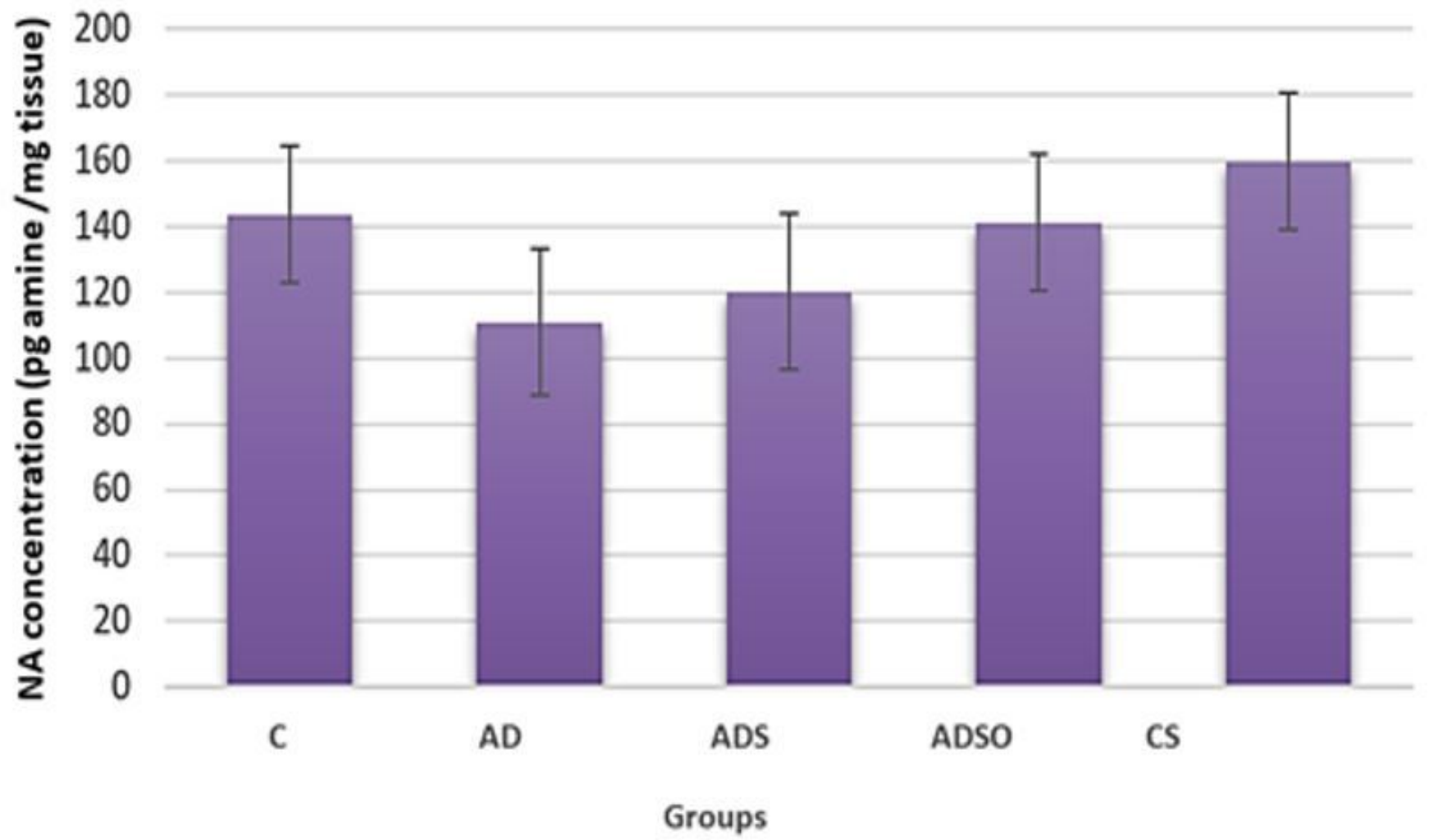

Figure 14

There was no significant difference between groups for NA concentration ( $p>0.05)$. 


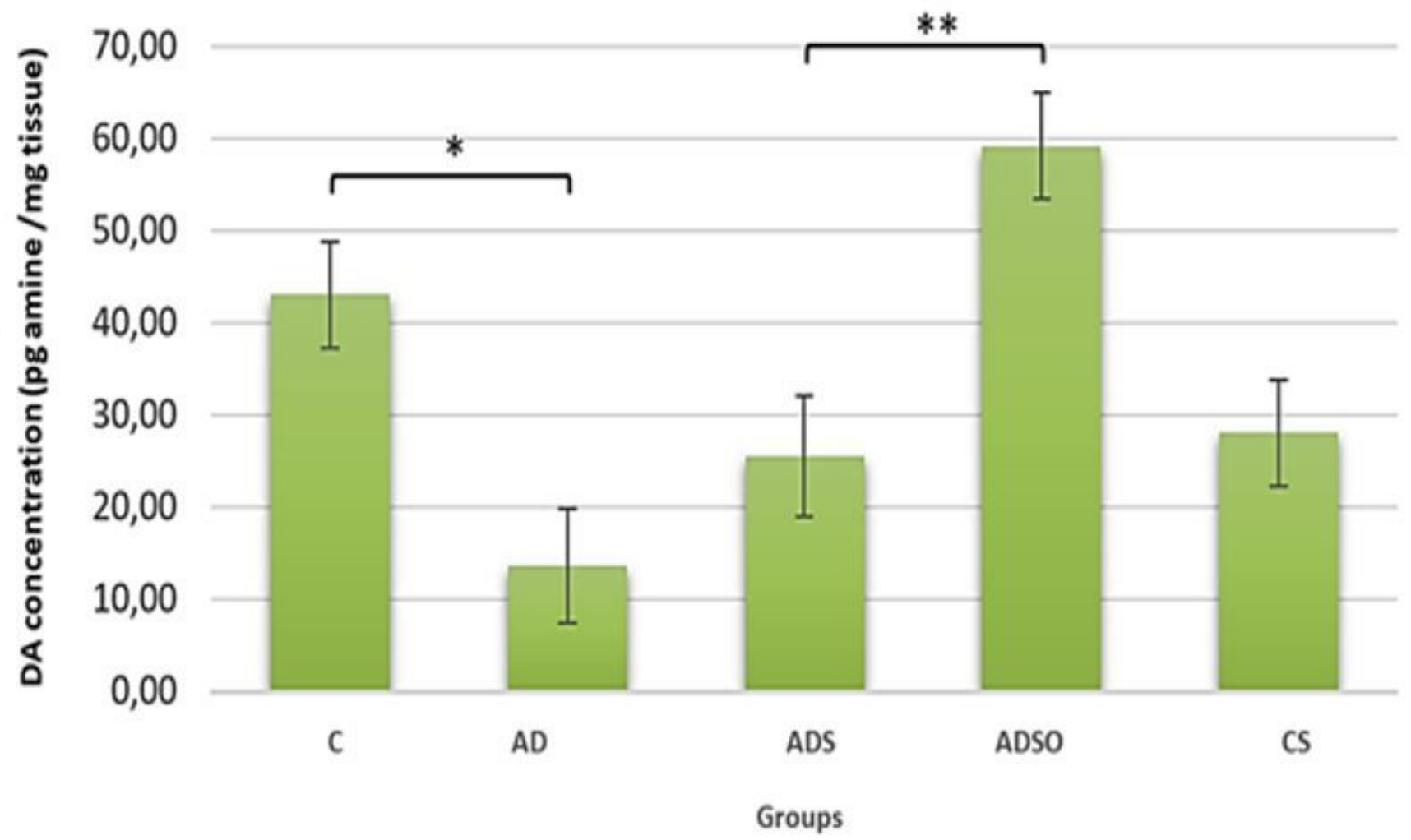

Figure 15

DA concentration was found to be significant between groups $(p<0.05)$. The $A D$ group was found to be significantly lower compared to the $C$ group, and the ADS group compared to the ADSO group $(*: p<0.05$, $\star *$ : $p<0.01)$. 